\title{
Effect of the Science Process Skills Laboratory Approach Supported with Peer-Instruction on Some of Science Process Skills of Pre-service Teachers
}

\author{
Aysel KOCAKÜLAH* \& Emre SAVAŞ
}

\author{
Balıkesir University, Balıkesir, TURKEY
}

Received : 15.01 .2013

Accepted : 28.11.2013

Abstract - Nowadays increasing importance of science process skills and laboratory approach in science education requires the acquisition of scientific process skills that teachers should have been gained those skills during pre-service training courses to transfer their students. Peer instruction, which results in effective outcomes for concept teaching recently, comprises another aspect of this study. The aim of this study is to determine whether scientific process skills laboratory approach, which is supported with peer instruction, is an effective method to improve some high level scientific process skills of pre-service teachers. Single group experimental research design was used in this study. Data were collected by using open ended experiment worksheets, student rubrics, experiment evaluation questionnaire and semi-structured interviews during peer instruction supported scientific process skills laboratory approach in which third year primary science education students at Balikesir University took part in six weeks long application. Findings of the study show that pre-service teachers' skills of determining variables, changing and controlling variables and making inferences improved while constructing hypotheses and setting up experiment skills were not improved. It is suggested that peer instruction supported scientific process skills laboratory approach should be used to acquire scientific process skills.

Key words: Science teaching, peer instruction, science process skills laboratory approach, pre-service teachers DOI No: http://dx.doi.org/10.12973/nefmed202

\section{Summary}

Introduction: Laboratory works are quite important in terms of learning and skill development in science education. Hoffstein and Lunetta (1982) have expressed that learning by doing is provided with the help of learning with experiment. Also teaching with experiment method is quite difficult. Both teachers' competences and material requirements, and also lack of suitable environment reduce the effectiveness of this method.

\footnotetext{
* Corresponding author: Aysel Kocakülah, Assistant Professor in Science Education, Faculty of Necatibey Education, Balıkesir University, 10100, Balıkesir, TURKEY.

E-mail: ayselko@balikesir.edu.tr
} 
Chipetta and Koballa (2002) have suggested various approaches to put this method in an effective position. One of them is science process skills laboratory approach. This approach is based on science process skills. Skills are intended to solve some of the problems in our daily life. Also skills are important in terms of scientific literacy. Therefore, these skills cannot be considered only for scientists. Of course, educators should also have this ability to develop these skills. This is also valid for pre-service teachers in the process of pre-service training.

The science process skills are classified in different ways in various sources. Progressivity is considered in classifications and it is generally observed that high-level skills are common and names of some high level skills are different. One of the common points of classifications is necessity to use most of these skills together in laboratory environment. Research concerning the science process skills, which has become the focus of researcher, reveals that the emphasis is on measurement and determination of these skills (Aydoğdu, 2006; Mbewe, Chabalengula \& Mumba, 2010) and development of these skills with some of the teaching techniques (Parim,2009; Bozdoğan, Demirbaş \& Taşdemir, 2006). With regard to this, Kanlı (2007) has applied 7E model-based laboratory approach and expressed that this method is effective in terms of developing the science process skills.

There are researches available showing that one of the strategy of active learning method is peer instruction which is an effective method in conceptual understanding and concept teaching (Ery1lmaz, 2004; Demirci, 2005; Sencar- Tokgöz, 2007). Peer-instruction, which is developed by Mazur (1997) and adopted to physics education, is used for teaching the concepts of physics course and it is concluded that this teaching techniques are effective. But when literature is reviewed, there are no research intended to integrate peer-instruction with laboratory environment or use peer-instruction in science process skills.

Based on all this, the aim of this research is to determine whether peer-instruction assisted science process skills laboratory approach is effective in developing high level of the science process skills of pre-service teachers. What is meant by high-level science process skills is the abilities that frequently encountered in the design and construction phase of an experiment like 'identifying variables, hypothesis-building, modifying and controlling variables, inference, and experimentation'. Considering that the participants of pre-service primary science teachers, the importance of acquiring these skills comes into prominence.

Methodology: Pre-test post-test single group semi- experimental design is used for the purpose of this study and open ended experiment worksheets and student rubrics are used as pre and post-test. The participants consisting of pre-service primary science teachers who are 
taught Science Teaching and Laboratory Applications which is one of the third grade courses at Balikesir University Necatibey Education Faculty in 2010-2011 academic year have been determined by using purposive sampling method (Yıldırım \& Şimşek, 2000). In this specified experiment groups consisting of 30 students, 10 groups consisting of 3 people have been created by researcher according to their success and willingness to perform an experiment.

Open ended experiment worksheets, student rubrics, experiment evaluation questionnaire and semi-structured interviews were used in order to obtain data. Open ended experiment worksheets were used by intending how students identify variables, make hypothesis, change and control variables to ensure them to show their inference skills. Open ended experiment worksheets, which were prepared in five different topics in terms of gaining skills for each week, were given 10 groups in a way that each two groups had one topic by using draw. The goal here is both intra-group cooperation and communion with the other group members. Students' rubrics are evaluation materials, consisting sub-skills between one and four points for each science process skills, using for evaluating their peers in the group, ensuring how many points should be given to each performance. Also they are used for the analysis of open ended experiment worksheets.

When the analyses of open-ended experiment worksheets and student rubrics are made, they have been turned into gain scores as individuals and groups. Equation of "normalized gain score" which has been defined by Hake (1998) and developed by Marx and Cummings (2007) has been used for gain score.

Data obtained from the experiment evaluation questionnaire by which the pre-service teachers evaluate themselves at the end of practice each week and semi-structured interviews conducted with 10 pre-service teachers have been encoded in the form of meaningful sentences. They have been shared as Experiment Evaluation Questionnaire Frequency and Percent Frequency values. The Experiment Evaluation Questionnaire and semi-structured interviews have been shared in a way that they promote to open-ended experiment worksheets and student rubrics.

The application of peer-instruction assisted laboratory approach to teaching lasted 10 weeks as two hours in a week. During the first four weeks, the pre-service teachers have been informed about the importance of laboratory study, experiment types, ways of designing and implementing an experiment and open-ended experiment worksheets. During the rest six weeks, applications have been made but first week was spent for trial. The gains determined in open-ended experiment worksheets have been determined according to Science Process 
Skills of $6^{\text {th }}, 7^{\text {th }}$ and $8^{\text {th }}$ grades about physics topics. 5 open-ended experiment worksheets have been prepared each week and pre-service teachers have been asked to follow that process. In that instance, pre-service teachers have designed their individual experiments first and then they have practiced with groups. The peers' exchange of views has been supported and exchanging views with another group taking the same open-ended experiment worksheets has been encouraged in case of disagreement. This part of the course is thought to be a period in which peer instruction occurs that is to say peers interact and convince each other (Mazur,1997). Thus, when pre-service teachers have made a decision, they designed and applied their experiment in the process. Student rubrics and experiment evaluation questionnaire in which they have evaluated the peers and groups were filled by the pre-service teachers at the evaluation stage.

Findings and Comments: In this part, findings referring if some science process skills of the pre-service teachers have developed or not with the applied teaching approach and the gain scores obtained from open-ended experiment worksheets and student rubrics have been included. The Table 1 shows gain scores obtained from open ended experiment worksheets and student rubrics.

Table 1 Gain scores obtained from open-ended experiment worksheets and student rubrics

\begin{tabular}{lll}
\hline Skills & Gain Scores & \\
& OEEW & SR \\
\hline Ability of identifying variables & 0,28 & 0,28 \\
Ability of drawing a conclusion & 0,71 & 0,19 \\
Ability of making an hypothesis & $-0,12$ & 0,21 \\
Ability of changing and controlling & 0,27 & 0,25 \\
variables & $-0,06$ & 0,36 \\
Ability of conducting an experiment &
\end{tabular}

When the gain scores are examined it can be seen in the Table 1 that low gain has been generated on the ability of identifying variables from open-ended experiment worksheets and student rubrics. Additionally, there is high gain from open-ended experiment worksheets and low gain from student rubrics for the ability of drawing conclusion. Findings show no gain from open-ended experiment worksheets and low gain from student rubrics for the ability of hypothesizing. There is also low gain from open-ended experiment worksheets and student rubrics for the ability of changing and controlling variables. It is found that there is no gain from open-ended experiment worksheets for the ability of conducting an experiment but there is average gain from student rubrics. It is thought that the discrepancy between open-ended 
experiment worksheets and student rubrics is due to the pre-service teachers act biased their peers and they have given missing scores in some cases when evaluating the skills of their peers because of rivalry within the group.

The findings obtained from experiment evaluation questionnaire mostly refer to the problems that pre-service teachers have had during the application of peer instruction-assisted teaching science process skills laboratory approach. 83,6 \% of pre-service teachers views indicate that students have experienced several problems throughout the instruction process.

Conclusion and Discussion: On the basis of the findings of this study, it can be concluded that the application of peer-instruction assisted teaching science process skills laboratory approach can develop some of the science process skills of pre-service science teachers. Gain scores obtained from open-ended experiment worksheets support the development of preservice teachers' scientific process skills. When the literature is examined, it has been observed that peer instruction improves the success of students in conceptual tests and their traditional problem solving abilities (Eryılmaz, 2004; Sencar-Tekgöz, 2007; Crouch \& Mazur, 2001). Moreover, it is concluded that peer-instruction method increases the students' comprehension level and develops their ability to synthesize by combining the parts (Cortright, Collins and DiCarlo, 2005). In the light of the literature review, science process skills laboratory approach has been integrated into peer instruction in this study. The findings obtained in this study show that peer-instruction assisted teaching laboratory approach has developed some of pre-service teachers' high-level scientific process skills. Finally, findings obtained from experiment evaluation questionnaire also indicate that pre-service teachers have been provided to experience some possible problems they encountered during the application before started serving as a primary science teacher.

Suggestions: In this part of the study, some suggestions have been made to prevent a number of problems encountered during the activation and implementation of the method used in this study to the pre-service science teachers. Although the method has provided a certain amount of increase in pre-service teachers' gain scores of science process skills, it is thought that it will give more effective results in terms of gain scores to focus on just one skill in open-ended experiment worksheets during each class hour. In addition, the application of the method, which is found to yield effective outcomes in terms of helping pre-service teachers to see their mistakes and deficiencies and the problems they encountered in this study, is thought to be repeated in other research or courses to increase the validity of the results of this study. 


\section{Akran Öğretimi Destekli Bilimsel Süreç Becerileri Laboratuvar Yaklaşımının Öğretmen Adaylarının Bazı Bilimsel Süreç Becerilerine Etkisi

\author{
Aysel KOCAKÜLAH ${ }^{\dagger}$ \& Emre SAVAŞ
}

Balıkesir Üniversitesi, Balıkesir, TÜRKİYE

Makale Gönderme Tarihi: 15.01.2013

Makale Kabul Tarihi: 28.11.2013

Özet - Fen bilimlerinde laboratuvar yaklaşımının ve bilimsel süreç becerilerinin öneminin arttığı günümüzde, bilimsel süreç becerilerinin kazandırılması açısından öğretmenlerin bilimsel süreç becerilerine sahip olması gerektiği, bunun da öğretmen adaylarına kazandırılarak sağlanabileceği düşünülmektedir. Son yıllarda kavram öğretiminde kullanımıyla etkili sonuçlar veren akran öğretimi de bu çalışmanın başka bir boyutunu oluşturmuştur. Bunlara dayalı olarak çalışmanın amacı, akran öğretimi destekli bilimsel süreç becerileri laboratuvar yaklaşımının, öğretmen adaylarının bazı üst düzey bilimsel süreç becerilerini geliştirmekte etkili bir yöntem olup olmadığını belirlemektir. Araştırmada tek gruplu deneysel desen kullanılmıştır. Balıkesir Üniversitesi, fen bilgisi öğretmenliği 3. sınıf öğrencileri ile 6 hafta boyunca devam eden akran öğretimi destekli bilimsel süreç becerileri laboratuvar yaklaşımı uygulamasında açık uçlu deney yaprakları, öğrenci rubrikleri, deney değerlendirme anketi ve yarı yapılandırılmış görüşme kayıtları ile veriler elde edilmiştir. Elde edilen bulgular sonucunda uygulamanın öğretmen adaylarının değişkenleri belirleme, değiş̧kenleri değiştirme ve kontrol etme ve sonuç çıkarma becerilerinde gelişme olduğu, hipotez kurma ve deney yapma becerilerinde ise gelişme olmadığ 1 görülmüş̧ür. Bu sonuca göre akran öğretimi destekli bilimsel süreç becerileri laboratuvar yaklaşımının bilimsel süreç becerilerinin kazandırılmasında uygulanması önerilmiştir.

Anahtar kelimeler: Fen öğretimi, akran öğretimi, bilimsel süreç becerileri laboratuvar yaklaşımı, öğretmen adaylar1

\section{Giriş}

Fen bilimlerinde laboratuvar çalışmalarının teorik bilgi ile uygulama arasında bir bağlantı oluşturarak, bazı bilimsel gerçeklerin gözlenmesinde dolayısıyla bilimsel bilginin öğretiminde kullanılan etkili bir yöntem olduğu bilinmektedir. Hofstein ve Lunetta (1982) ile Şensoy, Yalçın, Yıldırım ve Telli (2004) çalışmalarında öğretimde kullanılan deney yönteminin yaparak- yaşayarak öğrenmeyi sağladığını, öğrencilerin anlamlı öğrenmelerini desteklediğini belirtmiştir. Farklı çalışmalar da deney yönteminin öğrencilerin fen dersine

\footnotetext{
${ }^{\dagger}$ İletişim: Aysel Kocakülah, Yrd. Doç. Dr., İlköğretim Bölümü, Fen Bilgisi Eğitimi Anabilim Dalı, Necatibey Eğitim Fak., Balıkesir Üniversitesi, 10100, Balıkesir, TÜRKIYE

E-mail: ayselko@balikesir.edu.tr
} 
yönelik ilgilerini arttırdığını göstermektedir (Koray, Köksal, Özdemir \& Presley, 2007; Hofstain \& Lunetta, 2004; Palmer, 2006).

Pek çok açıdan laboratuvar çalışmaları fen öğretiminde etkili bir yöntem olmasına karşın, istenen başarının sağlanmasının önünde bir takım engellerle karşılaşılmaktadır. Birçok çalışmada bu engellerin başlıcalarının malzeme yetersizliği, kalabalık sınıflar, yeterli derslik olmayışı, zaman ve basılı kaynak yetersizliği olduğu belirtilmiştir (Ekici, Taşkın ve TaşkınEkici, 2002; Ekici, 2002; Ekici, 2006; Bayrak, 2006). Bahsedilen bu nedenlerden dolay1 öğretmenler laboratuvar yöntemini yeterince kullanmadıklarını ifade etmektedirler (Webb, 1993; Kocakülah ve Kocakülah, 2001; Chin ve Chia, 2006; Howit, 2007; Zion, Cohen ve Amir, 2007). Bu olumsuzlukların bir kısmının giderilmesinde öğretmenler tarafından çeşitli yaklaşımların kullanılabileceği önerilmektedir. $\mathrm{Bu}$ yaklaşımlar bilimsel süreç becerileri laboratuvar yaklaşımı, tümdengelim laboratuvar yaklaşımı, tümevarım laboratuvar yaklaşımı, problem çözme laboratuvar yaklaşımı, teknik beceriler laboratuvar yaklaşımı olarak say1labilir (Chippetta ve Koballa, 2002).

Bilimsel süreç becerileri laboratuvar yaklaşımında, öğrencilerin günlük hayatta karşılaştıkları sorunları çözmeye yönelik bir takım beceriler ele alınmaktadır. Ayrıca bu becerilerin öğrencilerin bilim okur- yazarı olmalarını sağladığı, bir takım problemleri kendi deneyimleri yoluyla çözme konusunda onlara yardımcı olduğu da bilinmektedir (Temiz, 2007). 2004 yılından itibaren yeniden yapılandırılan ilköğretim fen dersi programlarıyla da öğrencilerin iyi birer bilim okur- yazarı olarak yetiştirilmesinin gerekliliği ortaya konmaktadır (MEB, 200). Bu amaç için de bilimsel süreç becerileri fen ve teknoloji programının öğrenme alanlarından biri olarak karşımıza çıkmaktadır.

Bilimsel süreç becerilerine ilişkin alan-yazın incelendiğinde, bilimsel süreç becerilerinin çeşitli sınıflandırmalarının yapıldığı görülmektedir (Çepni, Ayas, Johnson ve Turgut, 1997; A.A.A.S., 1998; Lancour, 2005; MEB, 2006). Bu sınıflandırmalar dikkatle incelendiğinde temel süreç becerileri başlığının son yıllarda yapılan çalışmalarda hemen hemen ortak olduğu ve öğrencilere önceki sınıflarda kazandırılması gereken becerileri içerdiği göze çarpmaktadır (Walters ve Soyibo, 2001). Sınıflandırmalardaki temel farklılık ise öğrencilere sonradan kazandırılan üst düzey becerilerde karşımıza çıkmaktadır (Ergün, Şimşekli, Çalış, Özdilek, Göçmençelebi ve Şanlı, 2011).

Belirli bir amaca yönelik olarak gerçekleştirilen bir laboratuvar çalışmasında, bilimsel süreç becerilerinin bir kısmı beraber kullanılmaktadır (Settladge ve Southerland, 2007). Bu 
durumda pek çok temel süreç becerisini içeren üst düzey süreçlerden değişkenleri belirleme, hipotez kurma, değişkenleri değiştirme ve kontrol etme, sonuç çıkarma ve deney yapma becerilerinin sıklıkla laboratuvar çalışmalarında bir arada kullanılması gerektiği düşünülmektedir (Settladge ve Southerland, 2007). Bilimsel süreç becerilerinin son 10 yıldır eğitim araştırmacılarının odağı haline geldiği ve çeşitli ölçme teknikleri ile bilimsel süreç becerilerinin belirlenmesinin yanı sıra (Mbewe, Chabalengula ve Mumba 2010; BeaumontWalters ve Soyibo 2001; Aydoğdu, 2006), farklı öğretim teknikleri ile geliștirilmesine çalışıldığ1 görülmektedir. Genel anlamda bilimsel süreç becerileri üzerine odaklanılan araştırmaların (Parim, 2009; Bozdoğan, Demirbaş ve Taşdemir, 2006) yanında sadece üst düzey süreç becerilerinin geliştirilmesine yönelik araştırmalar da göze çarpmaktadır. Kanlı (2007) fen bilgisi öğretmenliği bölümündeki 81 öğrenciden 43 kişilik deney grubuna 7E modeli merkezli laboratuvar yaklaşımı, 38 kişilik kontrol grubuna ise doğrulama laboratuvar yaklaşımı uygulamış, deney grubundaki öğrencilerin üst düzey süreç becerilerinin daha fazla geliştiğini belirlemiştir. Michael ve Gifford (1995) üst düzey bilimsel süreç becerileri ile ilgili yaptıkları çalışmalarında ise 92 kişilik ortaöğretim öğrencilerine biyoloji dersinde bilgisayar destekli öğretim uygulamışlardır. Çalışma sonunda deney ve kontrol grubunun üst düzey süreç becerileri açısından grup puanlarında bir farklılık bulunamazken, bireysel cevaplarında bazı beceriler açısından deney grubunda daha fazla gelişim sağlandığı sonucuna ulaşılmıştır. Temel ve Morgil (2007) kimya öğretmenliğinde öğrenim gören 42 kişiye, laboratuvarda problem çözme temelli bir uygulama yapmış ve öğrencilerin hipotez kurma, işlemsel tanımlama, grafik çizme ve yorumlama gibi üst düzey süreç becerileri ön test ve sontest puanlarında anlamlı farklılıklar olduğunu gözlemlemişlerdir.

Son yıllarda, özellikle büyük yaş grupları ile yapılan birçok çalışmada akran öğretiminin kullanıldığı görülmektedir. Yapılan bir araştırmada akran öğretimi, işbirlikli öğrenme, aktif öğrenme, tutor ve geleneksel öğretim yöntemleri içerisinde akran öğretiminin öğrencilerin fizik dersine olan ilgilerini ve dersteki başarılarını arttırmada daha etkili olduğu sonucuna ulaşılmıştır (Demirci, 2005). Öğrencilerin yakın çevresindeki insanların onun öğrenmelerine büyük katkı sağladığı da bilinen bir gerçektir. Sosyal yapılandırmacı kurama göre de öğrenme sürecinde, sosyal ve kültürel çevre keşfetmeyi desteklemektedir (Vygotsky, 1978). Dolayısıyla akran öğretimi akranların birbirinden öğrenmelerini sağlayan, öğrenciler arasında sosyal ve yakın bir ilişkinin kurulduğu bir öğretim yöntemidir (Gözütok, 2007). Mazur (1997) akran öğretimini fizik öğretimine uyarlayarak geliştirmiş, akranların birbirinden öğrenmesi olgusunu kavramların öğrenilmesinde deneyerek, kavram öğretiminde akran 
öğretiminin etkili bir yöntem olduğu sonuca ulaşmıştır. Benzer çalışmalar da bu açıdan akran öğretimin etkili bir yöntem olduğunu desteklemektedir (Sencar- Tokgöz, 2007, Eryılmaz, 2004; Pilzer, 2001; Suppapittayaporn, Emarat ve Arayathaniykul, 2010). Yapılan alan-yazın taramaları sonucunda akran öğretimi ile bilimsel süreç becerilerinin geliştirilmesine yönelik herhangi bir çalışmaya ulaşılamamıştır. Ayrıca akran öğretiminin laboratuvar ortamına nasıl entegre edilebileceğine ilişkin bir çalışmaya da rastlanılamamıştır.

Bütün bu bahsedilenlerle birlikte araştırmanın amacı, akran öğretimi destekli bilimsel süreç becerileri laboratuvar yaklaşımının, öğretmen adaylarının bazı üst düzey bilimsel süreç becerilerini geliştirmekte etkili bir yöntem olup olmadığını incelemektir. Buradaki bazı üst düzey bilimsel süreç becerileri ile demek istenen, bir deneyin tasarlanması ve yapımı aşamasında sıklıkla karşılaşılan 'değişkenleri belirleme, hipotez kurma, değişkenleri değiştirme ve kontrol etme, sonuç çıkarma ve deney yapma' becerileridir. Ayrıca katılımcı grubunun fen bilgisi öğretmen adayları olduğu göz önüne alındığında bu becerilerin kazandırılmasının ne kadar önemli olduğu daha da ön plana çıkmaktadır.

\section{Yöntem}

\section{Araştırma Modeli}

$\mathrm{Bu}$ çalışmanın amacına uygun olarak; öntest- sontest, tek gruplu yarı deneysel desen kullanılmıştır. Öğrencilere öntest olarak bireysel Açık Uçlu Deney Yaprakları (AUDY) ve Öğrenci Rubrikleri (ÖR), sontest olarak da grup AUDY ve ÖR uygulanmıştır. Öntest ve sontest arasında bilimsel süreç becerilerini geliştirmeye yönelik akran öğretimi uygulanmıştır.

\section{Katılımcılar}

Bu çalışmaya 2010- 2011 eğitim öğretim yılında Balıkesir Üniversitesi, Necatibey Eğitim Fakültesi, Fen Bilgisi Öğretmenliği üçüncü sınıfında öğrenim gören ve Fen Öğretimi ve Laboratuvar Uygulamaları I dersini alan öğretmen adayları katılmıştır. Araştırmaya katılan öğrenciler amaçlı örnekleme yöntemlerinden ölçüt örnekleme ile seçilmiştir. Burada ölçüt veya ölçütler araştırmacı tarafından belirlenebildiği gibi daha önceden hazırlanan ölçüt listesi de kullanılabilmektedir (Yıldırım ve Şimşek, 2000).

Katılımcıların belirlenmesinde ölçüt olarak Dönmez' in (2007) çalışmasında kullandığı ve temel, nedensel ve deneysel süreç becerilerini ölçen sorulardan oluşan Bilimsel Süreç Becerileri (BSB) Testi kullanılmıştır. Araştırmaya katılacak öğretmen adaylarının en az temel süreç becerilerine sahip olmalarının gerekliliği düşünüldüğünden, temel süreç becerilerine 
ilişkin sorulara verilen doğru yanıtlar büyükten küçüğe doğru sıralanmıştır. İlk 30 öğretmen adayı gönüllülük ilkesi de gözetilerek çalışma grubuna seçilmiştir.

\section{Veri Toplama Araçları}

Araştırmada öğretmen adaylarına öntest ve sontest olarak uygulanan AUDY ve ÖR'nin yanı sıra Deney Değerlendirme Anketi (DDA) geliştirilmiştir. Ayrıca uygulama sonrasında öğretmen adayları ile yarı yapılandırılmış görüşmeler yapılarak diğer ölçme araçlarından elde edilen veriler daha detaylı bir biçimde sorgulanmaya çalışılmıştır.

Açık uçlu deney yaprakları (AUDY): Araştırmada 6., 7. ve 8. sınıf fen ve teknoloji dersi öğretim programında yer alan fizik konularına ilişkin ünitelerde yer alan kazanımlara odaklanıldığından, ölçme aracının geliştirilmesinde de bilimsel süreç becerilerinin en fazla olduğu kazanımlar seçilerek uygulamalar sırasında kullanılmak üzere ve her haftanın konu başlığına göre 5'er adet AUDY geliştirilmiştir.

AUDY ile öğretmen adaylarının değişkenleri belirleme, hipotez kurma, değişkenleri değiştirme ve kontrol etme, sonuç çıkarma ve deney yapma becerilerini kapsayan sorulara yanıt vererek deneyin yapılışını ifade etmelerini sağlamak amaçlanmıştır.

Öğrenci rubrikleri (ÖR): Öğretmen adaylarının deney süresince kullandıkları bilimsel süreç becerilerini ne oranda gösterdiklerini ve onlardan ne beklendiğini görmeleri amacı ile kullanılan rubrikler, aynı zamanda AUDY'nin analizinde de kullanılmıştır.

ÖR'de her bir beceriye ilişkin performans düzeylerinden en yüksek performans düzeyine 4, en düşüğüne de 1 puan verilerek akranlar önce birbirlerini değerlendirmiş, arkasından da grup değerlendirilmesi yapılmıştır. Öğretmen adaylarına uygulanan ÖR, özellikle onların beceri gelişim düzeylerinin belirlenmesine de katkı sağlamıştır.

Deney değerlendirme anketi (DDA): Öğretmen adaylarının her hafta hazırladıkları deneylere ilişkin düşüncelerini ve sürecin onlarına katkısını belirlemek üzere hazırlanmıştır. Anket açık uçlu 7 sorudan oluşmakta olup 6 hafta boyunca her ders sonunda öğrencilere uygulanmıştır.

Yarı yapılandırılmış görüşmeler: Çalışmada 30 öğretmen adayından 10'u ile görüşmeler yapılmış ve bu görüşmelerde sorulan akran öğretimi destekli bilimsel süreç becerileri laboratuvar yaklaşımına ilişkin 7 soru ile deney sürecinde yaşanan sıkıntılar, bilimsel süreç becerilerine ilişkin düşünceler, ders sürecindeki dikkat çekici kısımlar belirlenmeye çalışılmıştır. Yapılan görüşmeler ortalama 10- 15 dakika sürmüş ve öğretmen adaylarının izni ile ses kayıt cihazına kayıt edilmiştir. 


\section{Akran Öğretimi Destekli Laboratuvar Yaklaşımı}

Bu çalışma Fen Öğretimi ve Laboratuvar Uygulamaları I dersinde ve haftada iki saat olmak üzere toplam 10 hafta sürmüştür. Örneklemin belirlenmesi öncesindeki ilk dört hafta öğretim elemanı tarafından öğretmen adaylarına fen öğretimde laboratuvarın önemi ve amacı, deney çeşitleri, deney tasarlama teknikleri ve uygulama yolları, deney çalışma yaprağı çeşitlerinin tasarlanması ve hazırlanması konusunda bilgi verilmiştir. Ardından 6 haftalık uygulama sürecine geçilmiştir. Bu sürecin ilk haftası deneme uygulaması olarak belirlenmiş ve neler yapılacağı uygulamalı olarak öğrencilere açıklanmıştır. Ayrıca deneme uygulamasının yapıldığı ilk hafta 30 öğrenci 3 kişiden oluşan 10 gruba ayrılmıştır. Gruplar oluşturulurken öğretim üyesinin görüşleri doğrultusunda, her grupta başarılı ve deney yapma konusunda istekli bir öğrenci olmasına dikkat edilmiştir. Uygulamalar sırasında öğretmen adayları Fen Öğretimi ve Laboratuvar Uygulamaları I dersinin içeriğine bağlı olarak 6, 7 ve 8 . sınıf Fen ve Teknoloji dersi programında yer alan fizik konularının tamamına ilişkin etkinlikler gerçekleştirmiştir.

Dersin başında daha önce açıklandığı gibi oluşturulan AUDY, konuya ilişkin olarak her hafta beş tane hazırlanmış olup çekilişle 2 gruba aynı deney yaprağı gelecek şekilde dağıtılmıştır. Buradaki amaç, öğrencilerin grup içindeki akranlarının yanı sıra grup dışındaki akranlarından da faydalanmasını sağlamaktır.

Dersin gelişme aşamasında öğretmen adayları AUDY'i bireysel olarak doldurmuştur. $\mathrm{Bu}$ sayede öğretmen adayları deney tasarlama sürecine girmiş ve gereken becerileri kullanmaya başlamışlardır. Ardından grupların kendi içerisinde bir etkileşime girmesi ve grup içi tartışmaları desteklenmiştir. Bunun sonucunda öğretmen adayları nasıl bir deney yapacaklarına karar vermişledir. Ancak herhangi bir ortak fikir bulamayan ya da isteyen gruplar aynı deney yaprağı üzerinde çalışan diğer gruptaki arkadaşlarından veya güvendikleri başka bir akranından yardım almaları için teşvik edilmiştir. Yine de bir sonuca ulaşamayan öğretmen adaylarına öğretim üyesi ve araştırmacı tarafından yardım edilmiştir. Ortak bir karara varan öğretmen adayları AUDY'i grupla da doldurduktan sonra düzeneklerini kurarak deneylerini yapmışlardır.

Deneylerin tamamlanmasının ardından sonuç ve değerlendirme aşamasında ÖR dağıtılarak öğrencilerin gruptaki diğer 2 akranını ve genel olarak grubunu; DDA dağıtılarak konuyu ve deneylerini değerlendirmesi sağlanmıştır. 
Dersin gelişme bölümünde öğretmen adaylarının grup içerisinde etkileşime girmesi ve birbirini ikna etmeye teşvik söz konusudur. Burada akranlar yalnız grup içinde değil diğer gruplardaki akranlarıyla da etkileşim içine girmektedir. Bu etkileşim sonucunda fikir alışverişi ile akranların birbirlerinin deneyimlerinden faydalandıkları düşünülmektedir. Mazur (1997) akran öğretiminin gerçekleştiği yerin akranların birbiri ile etkileşimi ve birbirini ikna etmesi sürecinin gerçekleştiği yer olduğunu ifade etmektedir. Çalışmadaki akran öğretiminin vurgulandığ1 bölüm, her dersin gelişme aşamasına karşılık gelen tam da bu kısım olarak görülmektedir.

\section{Verilerin Analizi}

Öğrencilerin deney süreci boyunca doldurmuş oldukları AUDY'den elde edilen verilerin analizinde ÖR kullanılmıştır. Öncelikle AUDY'e verilen cevaplar içerik analizi ile analiz birimi cümleler olacak şekilde incelenmiştir. AUDY'de analiz birimlerine karşıllk gelen ve ÖR'deki her beceriye ilişkin performansların karşılığı 1 ile 4 arasında puanlarla ifade edilmiştir (Tablo 1).

Tablo 1. ÖR'deki Beceriler ile Bu Becerilere İlişkin Alt Performanslar ve Puanları

\begin{tabular}{|c|c|c|}
\hline Beceriler & Becerilere Ait Alt Performanslar & Puan \\
\hline $\begin{array}{c}\text { Değişkenleri } \\
\text { Belirleme }\end{array}$ & $\begin{array}{l}\text { Deneye iliş̧kin olarak, bağımsız ve bă̆ımlı değişken ile kontrol değiş̧kenden bahsedildi. } \\
\text { Deneydeki bağımlı ve bağımsız değişkenden bahsedildi. } \\
\text { Deneyde bağımlı değisken ya da bağımsız değişkenden bahsedildi. } \\
\text { Deneyde değişkenlerden bahsedilmedi. }\end{array}$ & $\begin{array}{l}4 \\
3 \\
2 \\
1\end{array}$ \\
\hline $\begin{array}{l}\text { Sonuç } \\
\text { Çıkarma }\end{array}$ & $\begin{array}{l}\text { Veriler yorumlandı, buna bağlı tam bir sonuç çıarılddı. } \\
\text { Veriler yorumlandı, buna bağll sonuç çıarılsa da eksikler vardı. } \\
\text { Verilerin eksik yorumlanmasina bağll eksik sonuç çıarıldl. } \\
\text { Herhangi bir sonuç çıarılamadı. }\end{array}$ & $\begin{array}{l}4 \\
3 \\
2 \\
1\end{array}$ \\
\hline $\begin{array}{l}\text { Hipotez } \\
\text { Kurma }\end{array}$ & $\begin{array}{l}\text { Deneyin amacina uygun olarak bir hipotez belirlendi ve test edildi. } \\
\text { Deneyin amacina uygun bir hipotez belirlendi ancak test etme aşamasında sikuntılar } \\
\text { yaşandl. } \\
\text { Deneyin amacina uygun olmayan bir hipotez belirlendi ve test edildi. } \\
\text { Herhangi bir hipotez belirlenemedi ve test edilemedi. }\end{array}$ & $\begin{array}{l}3 \\
2 \\
1\end{array}$ \\
\hline $\begin{array}{l}\text { Değişkenleri } \\
\text { Değiştirme } \\
\text { ve Kontrol } \\
\text { Etme }\end{array}$ & 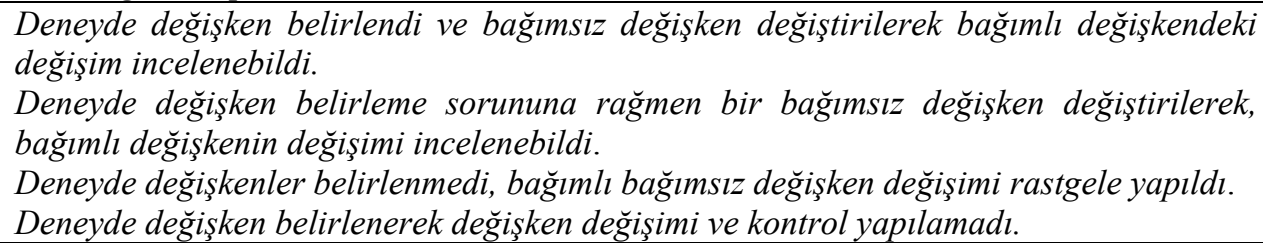 & $\begin{array}{l}3 \\
2 \\
1\end{array}$ \\
\hline $\begin{array}{l}\text { Deney } \\
\text { Yapma }\end{array}$ & 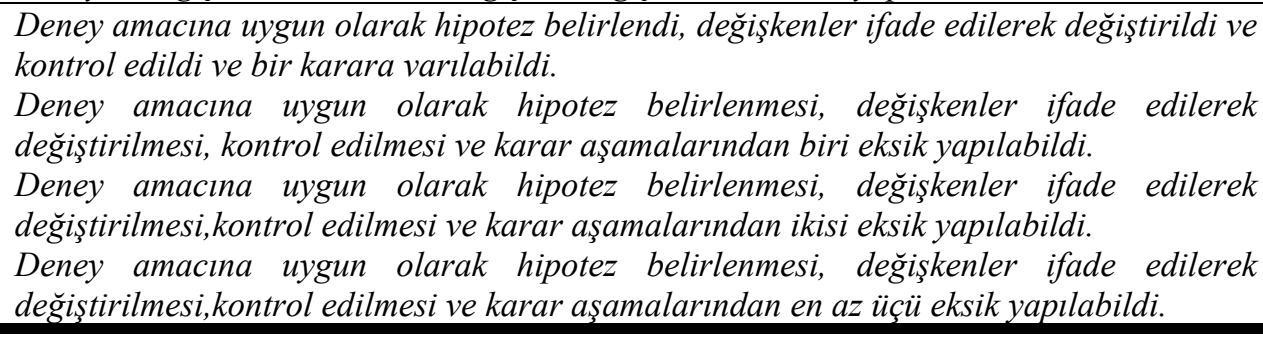 & 3 \\
\hline
\end{tabular}


Her beceri için ÖR'den ve AUDY'den bireysel ve grup puanları oluşturulmuştur. Elde edilen her bireysel puan ile grup puanı karşılaştırılarak kazanç skoru elde edilmiştir. Hake'in (1998) çalışmasında uygulamanın etkisini ifade ederken kullandığı kazanç skorunu, Marx ve Cummings (2007) geliştirmiş, normalleşmiş kazanç skoru olarak ifade etmiştir. Normalleştirilmiş kazanç skoruna $(<\mathrm{c}>$ ) ilişkin Denklem 1 aşağıda görülmektedir.

Denklem 1. Normalleştirilmiş Kazanç, Skoru

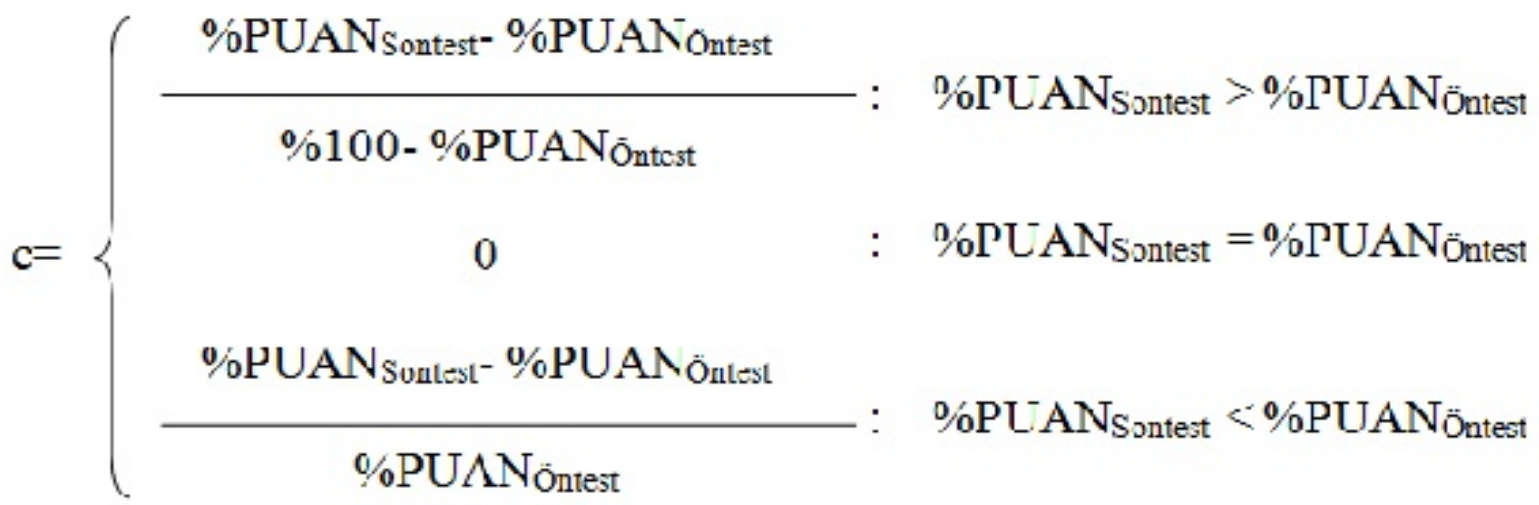

Denklem 1'den yararlanarak AUDY ve ÖR tabloları oluşturulmuştur. Bu tablolarda $\mathrm{c}<0$ için negatif kazanç skoru (kazanç olmadığı), $0<\mathrm{c}<0,3$ için düşük kazanç skoru (düşük kazanç) olduğu, 0,3<c<0,7 için kazancın orta kazanç skoru (orta değerde kazanç), $0,7<\mathrm{c}<1,0$ için yüksek kazanç skoru (kazanç yüksek) olarak değerlendirilmiştir. Elde edilen haftalık kazanç skorları ile de beceri toplam kazanç skorları elde edilmiş ve bunlar tablolarda paylaşılmıştır.

DDA'dan elde dilen verilerin analizinde öğretmen adaylarının verdiği cevaplar içerisinde anlamlı olan cümleler analiz birimi olarak kabul edilmiş ve içerik analizi yapılarak tablolar halinde öğretmen adaylarının görüş sıklıklarına göre yüzde ve frekans değerleri olarak bulgular kısmında paylaşılmıştır. Bazı sorular için frekans değerlerinin öğrenci sayısından fazla olduğu göze çarpmaktadır. $\mathrm{Bu}$ durum öğretmen adaylarının birden fazla görüş belirtmesinden kaynaklanmaktadır.

Yarı yapılandırılmış görüşmelerdeki 10 öğrencinin ses kayıtları yazılarak, anlamlı cümleler analiz birimi olacak şekilde analiz edilmiştir. Bu cümleler de diğer veri toplama araçlarından elde edilen verileri desteklemek üzere bulgular bölümünde yer yer paylaşılmıştır.

\section{Bulgular ve Yorumlar}

Çalışmanın bu bölümünde öğretmen adaylarının, bazı üst düzey bilimsel süreç becerilerinin uygulanan öğretim yaklaşımı ile geliştirilip geliştirilmeyeceğine ilişkin bulgular 
ele alınmıştır. Bu bulgular, her beceri için AUDY ve ÖR için sırasıyla verilmiş; ardından da DDA'dan elde edilen veriler sunulmuştur. Yarı yapılandırılmış görüşme formundan elde edilen veriler de sırası geldikçe paylaşılmıştır.

\section{AUDY ve ÖR'den Elde Edilen Bulgular}

AUDY ve ÖR'den elde edilen veriler değişkenleri belirleme, hipotez kurma, sonuç çıkarma, değişkenleri değiştirme ve kontrol etme ile deney yapma becerileri için önce AUDY sonra da ÖR gelecek şekilde sırasıyla verilmiştir.

Tablo 2 Öğretmen Adaylarının AUDY Bireysel (B) Puanları ile AUDY Grup (G) Puanlarında 'Değişkenleri Belirleme' Becerisine Ait Kazanç Skorları

\begin{tabular}{|c|c|c|c|c|c|c|c|c|c|c|c|c|c|}
\hline & \multirow{2}{*}{ Puan } & \multicolumn{2}{|c|}{ Konu 1} & \multicolumn{2}{|c|}{ Konu 2} & \multicolumn{2}{|c|}{ Konu 3} & \multicolumn{2}{|c|}{ Konu 4} & \multicolumn{2}{|c|}{ Konu 5} & \multicolumn{2}{|c|}{ Toplam } \\
\hline & & B & $\mathbf{G}$ & B & G & B & G & B & $\mathbf{G}$ & B & $\mathbf{G}$ & B & $\mathbf{G}$ \\
\hline & 4 & 8 & 4 & 12 & 7 & 19 & 8 & 10 & 9 & 9 & 3 & 58 & 31 \\
\hline & 3 & 8 & 1 & 4 & 0 & 3 & 0 & 7 & 1 & 0 & 1 & 22 & 3 \\
\hline & 2 & 7 & 4 & 11 & 3 & 3 & 2 & 11 & 0 & 18 & 6 & 50 & 15 \\
\hline & 1 & 0 & 1 & 0 & 0 & 2 & 0 & 1 & 0 & 3 & 0 & 6 & 1 \\
\hline & 胥 & $\begin{array}{l}\underset{n}{n} \\
\stackrel{\infty}{\infty}\end{array}$ & $\begin{array}{l}\text { ㅁ } \\
\text { ชิ }\end{array}$ & 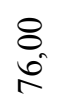 & $\begin{array}{l}8 \\
\curvearrowleft \\
\infty\end{array}$ & $\begin{array}{l}8 \\
\varnothing \\
\infty\end{array}$ & $\begin{array}{l}8 \\
8 \\
8\end{array}$ & $\begin{array}{l}\stackrel{\circ}{n} \\
\stackrel{N}{N}\end{array}$ & $\begin{array}{l}\stackrel{ }{n} \\
\hat{n}\end{array}$ & $\begin{array}{l}\text { ㅇ } \\
\text { ஷู }\end{array}$ & $\begin{array}{l}\stackrel{0}{n} \\
\hat{6}\end{array}$ & $\begin{array}{l}\stackrel{2}{\circ} \\
n \\
\end{array}$ & $\begin{array}{l}\stackrel{n_{n}}{\infty} \\
\stackrel{\infty}{2}\end{array}$ \\
\hline Kazanç & & $-0,20$ & & & & & & & & & & 0,2 & \\
\hline
\end{tabular}

Öğretmen adaylarının AUDY bireysel puanları ile AUDY grup puanlarında değişkenleri belirleme becerisi açısından elde edilen kazanç skorları Tablo 2'de görülmektedir. Değişkenleri belirleme becerisine ilişkin Tablo 2 incelendiğinde öğretmen adaylarının ortalama kazanç skorlarının düşük kazanç düzeyinde olduğu bulunmuştur $(<\mathrm{c}>=0,22)$. Bununla birlikte ilk hafta kazanç skorunun negatif değerde olduğu, sonraki iki hafta orta düzeyde kazanç elde ettikleri görülmektedir. Değişkenleri belirleme becerisine ilişkin en yüksek kazanç düzeyine 4 . hafta ulaşı1mıştır.

Değişkenleri belirleme becerisine ilişkin ÖR'den bireysel ve grup puanlarına ait kazanç skorları Tablo 3' de görülmektedir. Buradaki performanslar ve puanlar da AUDY'deki şekilde değerlendirilmiştir. Tablo 3 incelendiğinde öğretmen adaylarının haftalara göre orta düzey ve düşük düzeyde kazanç skorlarına sahip oldukları görülmektedir. En yüksek kazanç skoruna ilk hafta, en düşük kazanç skoruna da son hafta ulaştıkları belirlenmiştir. Öğretmen adaylarının bu beceriye ilişsin ortalama kazanç skoru ise düşük kazanç düzeyindedir $(<\mathrm{c}>=0,28)$. 
Tablo 3 Öğretmen Adaylarının ÖR Bireysel (B) Puanları ile ÖR Grup (G)

Puanlarında 'Değişskenleri Belirleme Becerisine Ait Kazanç Skorları

\begin{tabular}{|c|c|c|c|c|c|c|c|c|c|c|c|c|}
\hline \multirow[t]{2}{*}{ Puan } & \multicolumn{2}{|c|}{ Konu 1} & \multicolumn{2}{|c|}{ Konu 2} & \multicolumn{2}{|c|}{ Konu 3} & \multicolumn{2}{|c|}{ Konu 4} & \multicolumn{2}{|c|}{ Konu 5} & \multicolumn{2}{|c|}{ Toplam } \\
\hline & B & $\mathbf{G}$ & B & G & B & $\mathbf{G}$ & B & $\mathbf{G}$ & B & $\mathbf{G}$ & B & $\mathbf{G}$ \\
\hline 4 & 37 & 24 & 47 & 27 & 31 & 20 & 43 & 23 & 53 & 27 & 211 & 121 \\
\hline 3 & 7 & 2 & 3 & 1 & 17 & 7 & 12 & 6 & 7 & 3 & 46 & 19 \\
\hline 2 & 0 & 0 & 0 & 0 & 0 & 0 & 0 & 0 & 0 & 0 & 0 & 0 \\
\hline 1 & 0 & 0 & 0 & 0 & 0 & 0 & 1 & 0 & 0 & 0 & 1 & 0 \\
\hline 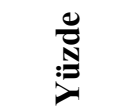 & $\begin{array}{l}8 \\
\text { ஜी }\end{array}$ & $\begin{array}{l}8 \\
\infty \\
\infty\end{array}$ & $\begin{array}{l}\stackrel{\circ}{n} \\
\infty \\
\Omega\end{array}$ & $\begin{array}{l}8 \\
\text { å }\end{array}$ & $\frac{n}{a}$ & $\stackrel{\circ}{n}$ & ๙̃ & $\frac{n}{\stackrel{n}{\sigma}}$ & $\begin{array}{l}8 \\
\hat{a}\end{array}$ & $\begin{array}{l}\stackrel{n}{n} \\
\hat{a}\end{array}$ & ๙ู & 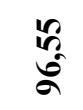 \\
\hline Kazanç & \multicolumn{2}{|c|}{0,50} & \multicolumn{2}{|c|}{0,33} & \multicolumn{2}{|c|}{0,26} & \multicolumn{2}{|c|}{0,22} & \multicolumn{2}{|c|}{0,17} & \multicolumn{2}{|c|}{$0,28 *$} \\
\hline
\end{tabular}

Değişkenleri belirleme becerisine ilişkin hem AUDY hem de ÖR'den elde edilen veriler düşük kazancın olduğunu göstermektedir. Öğretmen adayları ile yapılan görüşmeler incelendiğinde, 1 nolu öğretmen adayı "Genellikle değişkenleri belirlemede zorlandık. Grup arkadaşları ile sorun yaşadık çünkü fikirlerimiz uyuşmuyordu." derken; 2 nolu öğrenci ""Bizim için deney aşamasında en zor olan değişkenleri belirleme aşamasıydl, deneyde biz hiçbir şey bilmiyormuşuz gibi yeniden bulmaya çalıştık bu aşamada da zorlandık." demiştir.

Öğretmen adaylarının sonuç çıkarma becerilerinde AUDY bireysel ve grup puanlarından elde edilen bulgular Tablo 4'te görülmektedir.

Tablo 4 Öğretmen Adaylarının AUDY Bireysel (B) Puanları ile AUDY Grup (G) Puanlarında 'Sonuç Çıkarma' Becerisine Ait Kazanç Skorları

\begin{tabular}{|c|c|c|c|c|c|c|c|c|c|c|c|c|}
\hline \multirow[t]{2}{*}{ Puan } & \multicolumn{2}{|c|}{ Konu 1} & \multicolumn{2}{|c|}{ Konu 2} & \multicolumn{2}{|c|}{ Konu 3} & \multicolumn{2}{|c|}{ Konu 4} & \multicolumn{2}{|c|}{ Konu 5} & \multicolumn{2}{|c|}{ Toplam } \\
\hline & B & $\mathbf{G}$ & B & G & B & G & B & G & B & G & B & G \\
\hline 4 & 11 & 9 & 21 & 7 & 22 & 7 & 25 & 9 & 25 & 10 & 104 & 42 \\
\hline 3 & 2 & 1 & 1 & 3 & 3 & 3 & 0 & 1 & 1 & 0 & 7 & 8 \\
\hline 2 & 5 & 0 & 1 & 0 & 0 & 0 & 3 & 0 & 2 & 0 & 11 & 0 \\
\hline 1 & 5 & 0 & 4 & 0 & 2 & 0 & 1 & 0 & 2 & 0 & 14 & 0 \\
\hline 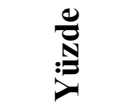 & $\stackrel{n}{\stackrel{2}{2}}$ & $\begin{array}{l}n \\
\hat{a}\end{array}$ & $\infty$ & $\begin{array}{c}n \\
\text { â }\end{array}$ & $\alpha$ & $\hat{n}$ & $\begin{array}{l}\text { त̂ } \\
\text { â }\end{array}$ & $\frac{n}{a}$ & $\frac{n}{2} \frac{2}{g}$ & 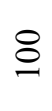 & $\frac{n}{\infty}$ & $\hat{\theta}_{0}^{0}$ \\
\hline Kazanç & & 91 & & & & & & 68 & & & & \\
\hline
\end{tabular}

Öğretmen adaylarının sonuç çıkarma becerisine ilişkin AUDY kazanç skorları incelediğinde ilk ve son haftalarda en yüksek kazanç skoruna ulaştıkları, 3. hafta ise en düşük 
kazanç skoruna ulaştıkları görülmektedir. $\mathrm{Bu}$ beceriye ilişkin ortalama kazanç skorunun yüksek kazanç dolaylarında olduğu görülmektedir $(<\mathrm{c}>=0,71)$.

Öğretmen adaylarının sonuç çıkarma becerisine ilişkin ÖR'den elde edilen bulguları Tablo 5'te görülmektedir.

Tablo 5 Öğretmen Adaylarının ÖR Bireysel (B) Puanları ile ÖR Grup

(G) Puanlarında 'Sonuç Çıkarma' Becerisine Ait Kazanç Skorları

\begin{tabular}{|c|c|c|c|c|c|c|c|c|c|c|c|c|}
\hline \multirow[t]{2}{*}{ Puan } & \multicolumn{2}{|c|}{ Konu 1} & \multicolumn{2}{|c|}{ Konu 2} & \multicolumn{2}{|c|}{ Konu 3} & \multicolumn{2}{|c|}{ Konu 4} & \multicolumn{2}{|c|}{ Konu 5} & \multicolumn{2}{|c|}{ Toplam } \\
\hline & B & $\mathbf{G}$ & B & G & B & $\mathbf{G}$ & B & $\mathbf{G}$ & B & $\mathbf{G}$ & B & $\mathbf{G}$ \\
\hline 4 & 33 & 20 & 40 & 23 & 31 & 15 & 39 & 23 & 46 & 25 & 189 & 106 \\
\hline 3 & 11 & 6 & 10 & 5 & 11 & 9 & 15 & 6 & 12 & 5 & 59 & 31 \\
\hline 2 & 0 & 0 & 0 & 0 & 6 & 3 & 0 & 0 & 2 & 0 & 8 & 3 \\
\hline 1 & 0 & 0 & 0 & 0 & 0 & 0 & 2 & 0 & 0 & 0 & 2 & 0 \\
\hline 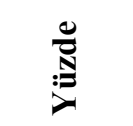 & $\frac{n}{n}$ & 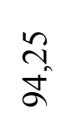 & $\begin{array}{l}8 \\
\approx \\
a\end{array}$ & $\begin{array}{l}n \\
n \\
n\end{array}$ & $\begin{array}{l}8 \\
\infty \\
\infty \\
\infty\end{array}$ & $\begin{array}{l}8 \\
8 \\
\infty\end{array}$ & $\frac{n}{2}$ & \begin{tabular}{l}
$n$ \\
\multirow{\sigma}{*}{}
\end{tabular} & $\begin{array}{l}\hat{a} \\
\text { }\end{array}$ & $\frac{n}{\hat{a}}$ & $\frac{n}{a}$ & $\begin{array}{l}6 \\
0 \\
0\end{array}$ \\
\hline Kazanç & \multicolumn{2}{|c|}{0,08} & \multicolumn{2}{|c|}{0,10} & \multicolumn{2}{|c|}{$-0,02$} & \multicolumn{2}{|c|}{0,43} & \multicolumn{2}{|c|}{0,67} & \multicolumn{2}{|c|}{$0,19 *$} \\
\hline
\end{tabular}

Tablo 5 incelendiğinde sonuç çıkarma becerisine ilişkin kazanç skorlarının haftalara göre oldukça fazla dalgalandığı görülmektedir. $\mathrm{Bu}$ beceriye ilişkin en yüksek kazanç skorunun son haftada en düşük kazanç skorunun da 3. hafta elde edildiği bulgulanmıştır. Ayrıca ortalama kazanç skorunun düşük düzeyde olduğu da bulgulanmaktadır $(<\mathrm{c}>=0,19)$.

ÖR ve AUDY'den elde edilen bulguların yanı sıra sonuç çıkarma becerisine ilişkin, 6 ve 7 numaralı öğrencilerden 6 nolu öğrenci "Sonuç çıkarma konusunda bazı deneylere ilişkin gözlem yapamamaktan dolayı sıkıntı çektik. Başka da sıkıntı çektiğimiz beceri yoktu."; 7 nolu öğrenci ise "Açıkça söylemek gerekirse sonuç çıkarmada zorlandık. Neye varacă̆ımızı anlayamadık bazen. Net olarak bir sonuca ulaşmakta bazılarında zorlanmasak da bazı deneylerde zorluk çektik." ifadelerini kullanmıştır. Bu becerilerin gösterilmesinde bazı öğretmen adaylarının sıkıntı yaşadığı, bazılarında kolaylıkla işin üstesinde geldiği görülmektedir.

Öğretmen adaylarının hipotez kurma becerisine ilişkin AUDY sonuçları incelenmiş burada elde edilenler Tablo 6'da paylaşılmıştır. Hipotez kurma becerisine ilişkin öğretmen adaylarının ifadeleri incelenerek elde edilen Tablo 6'daki ortalama kazanç skorlarından sadece 2. haftadaki kazanç skorunun en yüksek düzeyde; buna karşılık 4. haftanın ise en düşük düzeyde olduğu, ortalama kazancın da negatif düzeyinde olduğu görülmektedir $(<c>=-0,12)$. 
Tablo 6 Öğretmen Adaylarının AUDY Bireysel (B) Puanları ile AUDY Grup (G) Puanlarında 'Hipotez Kurma' Becerisine Ait Kazanç Skorlar1

\begin{tabular}{|c|c|c|c|c|c|c|c|c|c|c|c|c|}
\hline \multirow[t]{2}{*}{ Puan } & \multicolumn{2}{|c|}{ Konu 1} & \multicolumn{2}{|c|}{ Konu 2} & \multicolumn{2}{|c|}{ Konu 3} & \multicolumn{2}{|c|}{ Konu 4} & \multicolumn{2}{|c|}{ Konu 5} & \multicolumn{2}{|c|}{ Toplam } \\
\hline & B & $\mathbf{G}$ & B & $\mathbf{G}$ & B & $\mathbf{G}$ & B & G & B & G & B & G \\
\hline 4 & 22 & 7 & 24 & 10 & 22 & 5 & 26 & 8 & 27 & 8 & 121 & 38 \\
\hline 3 & 1 & 1 & 0 & 0 & 3 & 2 & 0 & 1 & 2 & 1 & 6 & 5 \\
\hline 2 & 0 & 1 & 3 & 0 & 1 & 1 & 3 & 0 & 0 & 0 & 7 & 2 \\
\hline 1 & 0 & 1 & 0 & 0 & 1 & 2 & 0 & 1 & 1 & 1 & 2 & 5 \\
\hline 氕 & $\begin{array}{l}0 \\
\text { aे }\end{array}$ & $\begin{array}{l}0 \\
\infty \\
\infty\end{array}$ & $\begin{array}{l}n \\
\dot{\sigma}\end{array}$ & \& & $\hat{n}$ & $\begin{array}{l}0 \\
i n\end{array}$ & $\begin{array}{l}\stackrel{2}{1} \\
\infty \\
a\end{array}$ & $\begin{array}{l}\circ \\
\text { \& }\end{array}$ & $\frac{n}{n}$ & $\begin{array}{l}\circ \\
\stackrel{\circ}{\circ}\end{array}$ & ஜ̊ & $\begin{array}{l}b \\
\dot{\infty}\end{array}$ \\
\hline Kazanç & \multicolumn{2}{|c|}{$-0,31$} & \multicolumn{2}{|c|}{1,00} & \multicolumn{2}{|c|}{$-0,19$} & \multicolumn{2}{|c|}{$-0,08$} & \multicolumn{2}{|c|}{$-0,06$} & \multicolumn{2}{|c|}{$-0,12 *$} \\
\hline
\end{tabular}

Hipotez kurma becerisine ilişkin ÖR'den elde edilen kazanç skorları Tablo 7'de görülmektedir. Tablo 7 incelendiğinde öğretmen adaylarının en yüksek kazanç skorlarının 2. hafta en düşük kazanç skorlarının da son haftada olduğu; ortalama kazançlarının da düşük seviyede gerçekleştiği görülmektedir $(<\mathrm{c}>=0,21)$.

Tablo 7 Öğretmen Adaylarının ÖR Bireysel (B) Puanları ile ÖR Grup (G) Puanlarında 'Hipotez Kurma' Becerisine Ait Kazanç Skorları

\begin{tabular}{|c|c|c|c|c|c|c|c|c|c|c|c|c|}
\hline \multirow[t]{2}{*}{ Puan } & \multicolumn{2}{|c|}{ Konu 1} & \multicolumn{2}{|c|}{ Konu 2} & \multicolumn{2}{|c|}{ Konu 3} & \multicolumn{2}{|c|}{ Konu 4} & \multicolumn{2}{|c|}{ Konu 5} & \multicolumn{2}{|c|}{ Toplam } \\
\hline & B & $\mathbf{G}$ & B & $\mathbf{G}$ & B & $\mathbf{G}$ & B & G & B & $\mathbf{G}$ & B & G \\
\hline 4 & 35 & 21 & 34 & 22 & 28 & 17 & 41 & 23 & 38 & 19 & 176 & 102 \\
\hline 3 & 9 & 5 & 16 & 6 & 15 & 9 & 14 & 6 & 20 & 10 & 74 & 36 \\
\hline 2 & 0 & 0 & 0 & 0 & 4 & 1 & 0 & 0 & 2 & 2 & 6 & 3 \\
\hline 1 & 0 & 0 & 0 & 0 & 1 & 0 & 1 & 0 & 0 & 0 & 2 & 0 \\
\hline 氕 & $\frac{n}{n}$ & $\begin{array}{l}8 \\
\curvearrowleft \\
\curvearrowleft\end{array}$ & $\begin{array}{l}8 \\
\text { a }\end{array}$ & $\frac{n}{\stackrel{n}{\sigma}}$ & $\begin{array}{l}\stackrel{0}{n} \\
\mathfrak{n}^{\circ} \\
\end{array}$ & $\frac{n}{2}$ & $\begin{array}{l}\text { กิ } \\
\text { â }\end{array}$ & $\frac{n}{\stackrel{n}{\sigma}}$ & $\begin{array}{l}8 \\
8 \\
8\end{array}$ & $\begin{array}{l}8 \\
8 \\
\circ\end{array}$ & $\begin{array}{l}\mathscr{\alpha} \\
\hat{\sigma}\end{array}$ & 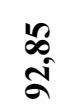 \\
\hline Kazanç & \multicolumn{2}{|c|}{0,20} & \multicolumn{2}{|c|}{0,34} & \multicolumn{2}{|c|}{0,24} & \multicolumn{2}{|c|}{0,30} & \multicolumn{2}{|c|}{0,00} & \multicolumn{2}{|c|}{$0,21 *$} \\
\hline
\end{tabular}

Hipotez kurma becerisine ilişkin öğretmen adayları ile yapılan görüşmelerden 5 nolu öğretmen adayının görüşleri : "Daha çok, deneye ilişkin hipotez kurma aşamasında zorlandık. Hangi hipotezi kullanacağımıza karar veremiyorduk. Bu konuda bir karmaşa yaşıyorduk", 9 nolu öğretmen adayı da "Daha önce böyle şeyler denemediğimiz için değişkenleri belirleme ve hipotez kurmada zorlandı, deney problemleri hakkında da önceden araştırma 
yapamıyorduk", 7 nolu öğretmen adayı da "Hipotez denemeye açık olmalı, çünkü doğru çıkmayabilir her zaman. Malzeme hatası, ortam şartlarından kaynaklanan hatalar olabilir. Bu nedenle denemeye yönelik olmall, sonuca yönelik olmall. Genellikle soru cümlesi olacak şekilde hipotez kurulmalı..." şeklinde görüşlerini ifade etmektedir. Yapılan görüşmeler bir hipotezin nasıl ifade edilmesi gerektiğine ilişkin öğretmen adaylarının yeteri kadar bilgilerinin bulunmadığını ve bu aşamada oldukça sıkıntı çektiklerini göstermektedir.

Öğretmen adaylarının değişkenleri değiştirme ve kontrol etme becerisine ilişkin AUDY bireysel ve grup puanlarından elde edile kazanç skorları Tablo 8'de görülmektedir.

Tablo 8 Öğretmen Adaylarının AUDY Bireysel (B) Puanları ile AUDY Grup (G) Puanlarında 'Değişkenleri Değiştirme ve Kontrol Etme' Becerisine Ait Kazanc Skorları

\begin{tabular}{|c|c|c|c|c|c|c|c|c|c|c|c|c|}
\hline \multirow[t]{2}{*}{ Puan } & \multicolumn{2}{|c|}{ Konu 1} & \multicolumn{2}{|c|}{ Konu 2} & \multicolumn{2}{|c|}{ Konu 3} & \multicolumn{2}{|c|}{ Konu 4} & \multicolumn{2}{|c|}{ Konu 5} & \multicolumn{2}{|c|}{ Toplam } \\
\hline & B & G & B & G & B & G & B & G & B & G & B & G \\
\hline 4 & 15 & 4 & 17 & 7 & 22 & 8 & 17 & 9 & 9 & 4 & 80 & 32 \\
\hline 3 & 7 & 6 & 2 & 3 & 0 & 1 & 10 & 1 & 19 & 4 & 38 & 15 \\
\hline 2 & 0 & 0 & 8 & 0 & 3 & 1 & 1 & 0 & 1 & 2 & 13 & 3 \\
\hline 1 & 1 & 0 & 0 & 0 & 2 & 0 & 1 & 0 & 1 & 0 & 5 & 0 \\
\hline 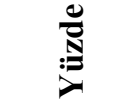 & $\begin{array}{l}\tilde{a} \\
\hat{\infty}\end{array}$ & $\begin{array}{l}8 \\
\infty \\
\infty\end{array}$ & $\stackrel{\sim}{\sim}$ & $\begin{array}{l}\text { ำ } \\
\text { ๙ิ }\end{array}$ & $\begin{array}{l}8 \\
\infty \\
\infty\end{array}$ & $\begin{array}{l}\stackrel{2}{n} \\
\text { ล̊ }\end{array}$ & $\begin{array}{l}8 \\
\infty \\
\infty\end{array}$ & $\begin{array}{l}\stackrel{n}{n} \\
\hat{a}\end{array}$ & $\begin{array}{l}8 \\
\varnothing \\
\infty\end{array}$ & $\begin{array}{l}8 \\
\infty \\
\infty\end{array}$ & $\frac{R}{\infty}$ & 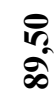 \\
\hline Kazanç & \multicolumn{2}{|c|}{$-0,05$} & \multicolumn{2}{|c|}{0,55} & \multicolumn{2}{|c|}{0,32} & \multicolumn{2}{|c|}{0,81} & \multicolumn{2}{|c|}{0,0} & \multicolumn{2}{|c|}{$0,27 *$} \\
\hline
\end{tabular}

Tablo 8'deki kazanç skorları incelendiğinde 1. haftaki kazanç skorunun en düşük düzeyde; 4. haftanın ise en yüksek düzeyde olduğu görülmüştür. Öğretmen adaylarının ortalama kazancının da düşük düzeyinde olduğu görülmektedir $(<\mathrm{c}>=0,27)$.

Değişkenleri değiştirme ve kontrol etme becerisine ilişskin ÖR'den elde edilen sonuçlar Tablo 9'da görülmektedir. Bu beceriye ilişkin performans ve puanlar AUDY'deki hipotez kurma becerisindeki gibidir.

Öğretmen adaylarının cevaplarında elde edilen ÖR bulgularına ilişkin Tablo 9 incelendiğinde en düşük kazancın 4. hafta en yüksek kazancın da 2. hafta olduğu görülmektedir. Ancak buna rağmen haftalara göre kazanç skorlarında çok fazla bir farklılaşma görülmemekte olup öğretmen adaylarının ortalama kazançlarının düşük kazanç düzeyinde olduğu görülmektedir $(<\mathrm{c}>=0,25)$.

Öğretmen adaylarının değişkenleri değiştirme ve kontrol etme becerisine ilişkin yarı yapılandırılmış görüşmelerdeki ifadeleri incelendiğinde, 6 nolu öğretmen adayının " Beceriler 
açısından değişkenleri belirleme konusunda sıkıntı oldu. Hangi değişkeni sabit tutacaksak onun ne olduğunu belirleme ve sabit tutmada sıkıntı çektik. " ve 10 nolu öğretmen adayının da

Tablo 9 Öğretmen Adaylarının ÖR Bireysel (B) Puanları ile ÖR Grup

(G) Puanlarında 'Değişkenleri Değiştirme ve Kontrol Etme' Becerisine Ait Kazanç Skorları

\begin{tabular}{|c|c|c|c|c|c|c|c|c|c|c|c|c|}
\hline \multirow[t]{2}{*}{ Puan } & \multicolumn{2}{|c|}{ Konu 1} & \multicolumn{2}{|c|}{ Konu 2} & \multicolumn{2}{|c|}{ Konu 3} & \multicolumn{2}{|c|}{ Konu 4} & \multicolumn{2}{|c|}{ Konu 5} & \multicolumn{2}{|c|}{ Toplam } \\
\hline & B & G & B & G & B & G & B & G & B & G & B & G \\
\hline 4 & 38 & 24 & 42 & 25 & 31 & 21 & 44 & 23 & 41 & 23 & 196 & 116 \\
\hline 3 & 4 & 1 & 8 & 3 & 15 & 5 & 11 & 6 & 19 & 7 & 57 & 22 \\
\hline 2 & 0 & 1 & 0 & 0 & 1 & 1 & 0 & 0 & 0 & 0 & 1 & 2 \\
\hline 1 & 0 & 0 & 0 & 0 & 1 & 0 & 1 & 0 & 0 & 0 & 2 & 0 \\
\hline 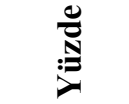 & $\begin{array}{l}\stackrel{2}{n} \\
\text { }\end{array}$ & $\begin{array}{l}\stackrel{2}{n} \\
\hat{a}\end{array}$ & $\begin{array}{l}8 \\
8 \\
8\end{array}$ & $\begin{array}{l}\stackrel{2}{a} \\
\hat{a}\end{array}$ & $\begin{array}{l}\text { ñ. } \\
\text { ळे }\end{array}$ & $\begin{array}{l}\stackrel{n}{n} \\
\text { á }\end{array}$ & $\frac{n}{n}$ & $\begin{array}{l}\stackrel{n}{a} \\
d\end{array}$ & $\begin{array}{l}8 \\
\text { â }\end{array}$ & $\begin{array}{l}8 \\
+\end{array}$ & $\begin{array}{l}n \\
\hat{n} \\
\text { ñ }\end{array}$ & $\frac{10}{2}$ \\
\hline Kazanç & & & & 31 & & & & & & & & \\
\hline
\end{tabular}

" Değişkenleri belirlemede sıkıntı yaşıyorduk, tabii ki değişkenleri değiştirme ve kontrol etme becerisi de sıkıntılı oluyor bunun dışında sıkıntı çekilen bir beceri yok." şeklinde görüşlerini belirttikleri görülmektedir. Bu görüşlerin onların değişkenleri değiştirme ve kontrol etme becerisinin, değişkenleri belirlemelerine bağlı olduğunun farkında olduklarını göstermektedir.

Öğretmen adaylarının AUDY'deki deney yapma becerilerine ilişkin bireysel ve grup puanlarından elde edilen kazanç skorları Tablo 10'da görülmektedir.

Tablo 10 Öğretmen Adaylarının AUDY Bireysel (B) Puanları ile AUDY Grup (G) Puanlarında 'Deney Yapma' Becerisine Ait Kazanç Skorları

\begin{tabular}{|c|c|c|c|c|c|c|c|c|c|c|c|c|}
\hline \multirow[t]{2}{*}{ Puan } & \multicolumn{2}{|c|}{ Konu 1} & \multicolumn{2}{|c|}{ Konu 2} & \multicolumn{2}{|c|}{ Konu 3} & \multicolumn{2}{|c|}{ Konu 4} & \multirow{2}{*}{$\begin{array}{c}\text { Konu } 5 \\
\text { B } \\
\end{array}$} & \multicolumn{3}{|c|}{ Toplam } \\
\hline & B & $\mathbf{G}$ & B & $\mathbf{G}$ & B & $\mathbf{G}$ & B & $\mathbf{G}$ & & $\mathbf{G}$ & B & $\mathbf{G}$ \\
\hline 4 & 13 & 1 & 13 & 6 & 18 & 5 & 17 & 7 & 20 & 1 & 81 & 20 \\
\hline 3 & 4 & 4 & 10 & 4 & 7 & 3 & 8 & 3 & 6 & 4 & 35 & 18 \\
\hline 2 & 6 & 5 & 4 & 0 & 0 & 2 & 4 & 0 & 4 & 5 & 18 & 12 \\
\hline 1 & 0 & 0 & 0 & 0 & 2 & 0 & 0 & 0 & 0 & 0 & 2 & 0 \\
\hline 촗 & î & 0 & $\tilde{\infty}^{2}$ & $\stackrel{\circ}{8}$ & $\frac{\sigma}{\infty}$ & in & $\begin{array}{l}\bar{\imath} \\
\text { }\end{array}$ & â & $\begin{array}{l}m \\
\cdots \\
\infty \\
\infty\end{array}$ & 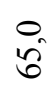 & $\begin{array}{l}\stackrel{n}{*} \\
\stackrel{\infty}{\infty}\end{array}$ & श \\
\hline Kazanç & & & & & & & & & $-0,26$ & & & \\
\hline
\end{tabular}

Deney yapma becerisine ilişskin Tablo 10 incelendiğinde öğretmen adaylarının 4. hafta en yüksek kazancı sağladığını; son hafta ise en düşük kazanç skorunda oldukları 
görülmektedir. Öğretmen adaylarının ortalama kazançlarının da negatif kazanç düzeyinde olduğu görülmektedir $(<\mathrm{c}>=-0,06)$.

Deney yapma becerisine ilişkin öğretmen adaylarının ÖR kazanç skorları Tablo 10'da görülmektedir. Öğretmen adaylarının deney yapma becerisini değerlendirmeleri ile ilgili olarak Tablo 11 incelendiğinde 2. hafta kazancın en yüksek olduğu, son hafta da kazanç skorunun en düşük olduğu görülmektedir. Bu beceriye ilişkin ortalama kazancın ise orta düzeyde olduğu görülmektedir $(<\mathrm{c}>=0,36)$.

Tablo 11 Öğretmen Adaylarının ÖR Bireysel (B) Puanları ile ÖR Grup

(G) Puanlarında 'Deney Yapma' Becerisine Ait Kazanç Skorları

\begin{tabular}{|c|c|c|c|c|c|c|c|c|c|c|c|c|}
\hline \multirow[t]{2}{*}{ Puan } & \multicolumn{2}{|c|}{ Konu 1} & \multicolumn{2}{|c|}{ Konu 2} & \multicolumn{2}{|c|}{ Konu 3} & \multicolumn{2}{|c|}{ Konu 4} & \multicolumn{2}{|c|}{ Konu 5} & \multicolumn{2}{|c|}{ Toplam } \\
\hline & B & $\mathbf{G}$ & B & G & B & $\mathbf{G}$ & B & $\mathbf{G}$ & B & $\mathbf{G}$ & B & $\mathbf{G}$ \\
\hline 4 & 35 & 22 & 38 & 28 & 31 & 21 & 42 & 22 & 47 & 23 & 193 & 116 \\
\hline 3 & 8 & 4 & 12 & 0 & 14 & 5 & 13 & 7 & 12 & 7 & 59 & 23 \\
\hline 2 & 0 & 0 & 1 & 0 & 2 & 1 & 0 & 0 & 1 & 0 & 4 & 1 \\
\hline 1 & 0 & 0 & 0 & 0 & 1 & 0 & 1 & 0 & 0 & 0 & 2 & 0 \\
\hline 疍 & 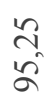 & $\begin{array}{l}\text { ป̂ } \\
\text { ๙̊ }\end{array}$ & $\begin{array}{c}\text { ñ } \\
\text { ñ }\end{array}$ & $\stackrel{0}{8}$ & $\stackrel{\circ}{\infty}$ & ๙n & $\frac{n}{a}$ & \begin{tabular}{l}
0 \\
\multirow{2}{*}{}
\end{tabular} & \begin{tabular}{l}
$\stackrel{2}{2}$ \\
\multirow{2}{}{}
\end{tabular} & \begin{tabular}{l}
$\stackrel{2}{2}$ \\
\multirow{2}{}{}
\end{tabular} & 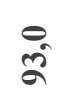 & ஜू \\
\hline Kazanç & \multicolumn{2}{|c|}{0,21} & \multicolumn{2}{|c|}{1,00} & \multicolumn{2}{|c|}{0,41} & \multicolumn{2}{|c|}{0,17} & \multicolumn{2}{|c|}{0,00} & \multicolumn{2}{|c|}{$0,36 *$} \\
\hline
\end{tabular}

Öğretmen adayları ile yapılan görüşmelerden deney yapma becerisine ilişkin elde edilenler incelendiğinde: 10 nolu öğretmen adayının " Birkaç deneyde deneyi yapmada sıkıntı çektik. Her şey beklediğimiz gibi olmadl, kurulan düzenek, şekil üzerinde kurulan düzeneğe uymadl. Oluşturduğumuz modelde bir deney yapamadık" görüşünde olduğu görülmektedir. Buradan öğretmen adaylarının düzenek kurmakta yer yer zorlandıkları ortaya çıkmaktadır.

\section{Deney Değgerlendirme Anketinden Elde Edilen Bulgular}

$\mathrm{Bu}$ bölümde her dersin sonunda öğretmen adaylarının deneyleri yaparken karşılaştıkları sorunları ve deneyler hakkındaki değerlendirmelerini ortaya koymayı amaçlayan DDA' dan elde edilen bulgular paylaşılmıştır.

Öğretmen adaylarının yapmış oldukları deney sonuçlarına etki eden faktörlere yönelik düşüncelerine ilişkin görüşleri Tablo 12 'de görülmektedir. Buna göre öğretmen adaylarının \%83,64 oranında deney esnasında bir takım hatalar yapıldığından bahsettikleri görülmektedir. Bu hataların; ölçüm ya da aletlerin çalışmamasından kaynaklandığını ifade eden öğretmen adaylarının oranı \%28,48 sonucun gözlemlenememesinden ya da ölçülecek niceliğin yeterli olmamasından kaynaklanan hatalardan bahsedenlerin ise \%15,76 olduğu görülmektedir. Deney esnasında bir hata yapmadığından bahseden öğretmen adayları da \%15,7'dir. 
Tablo 12 Öğretmen Adaylarının Yaptıkları Deneylerde Sonuçlara Etki Eden Hata Faktörlerine İlişkin DDA Sonuçları

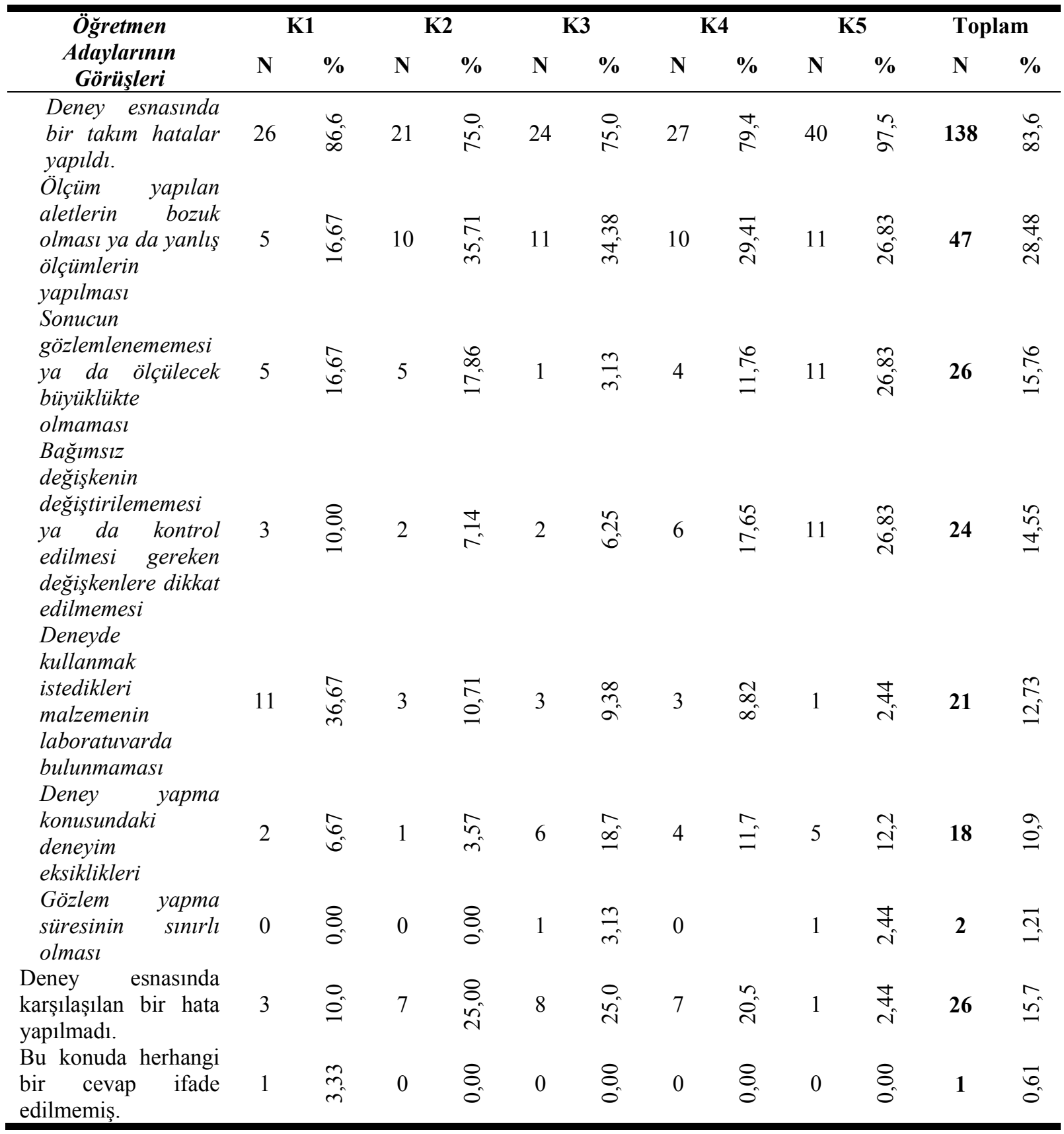

DDA'daki öğretmen adaylarının deney yaparken sonuçlara etki eden hata faktörlerine karşı aldıkları önlemlere ilişkin soru hakkındaki görüşleri Tablo 13'de görülmektedir. Tablo 13 incelendiğinde, öğretmen adaylarının bu hatalara ilişkin olarak \%55,54 ünün bir önlem aldığı, geri kalan öğretmen adayının da her hangi bir önlem almadığı görülmektedir. Önlem alan öğretmen adaylarının da \%40'ı ölçümleri tekrarlamak şeklinde çözüm ürettiklerini ifade etmiştir. 
Tablo 13 Öğretmen Adaylarının Yaptıkları Deneylerde Sonuçlara Etki Eden Hata Faktörlerinin Etkisini Azaltmak İçin Yaptığg Çalışmalar

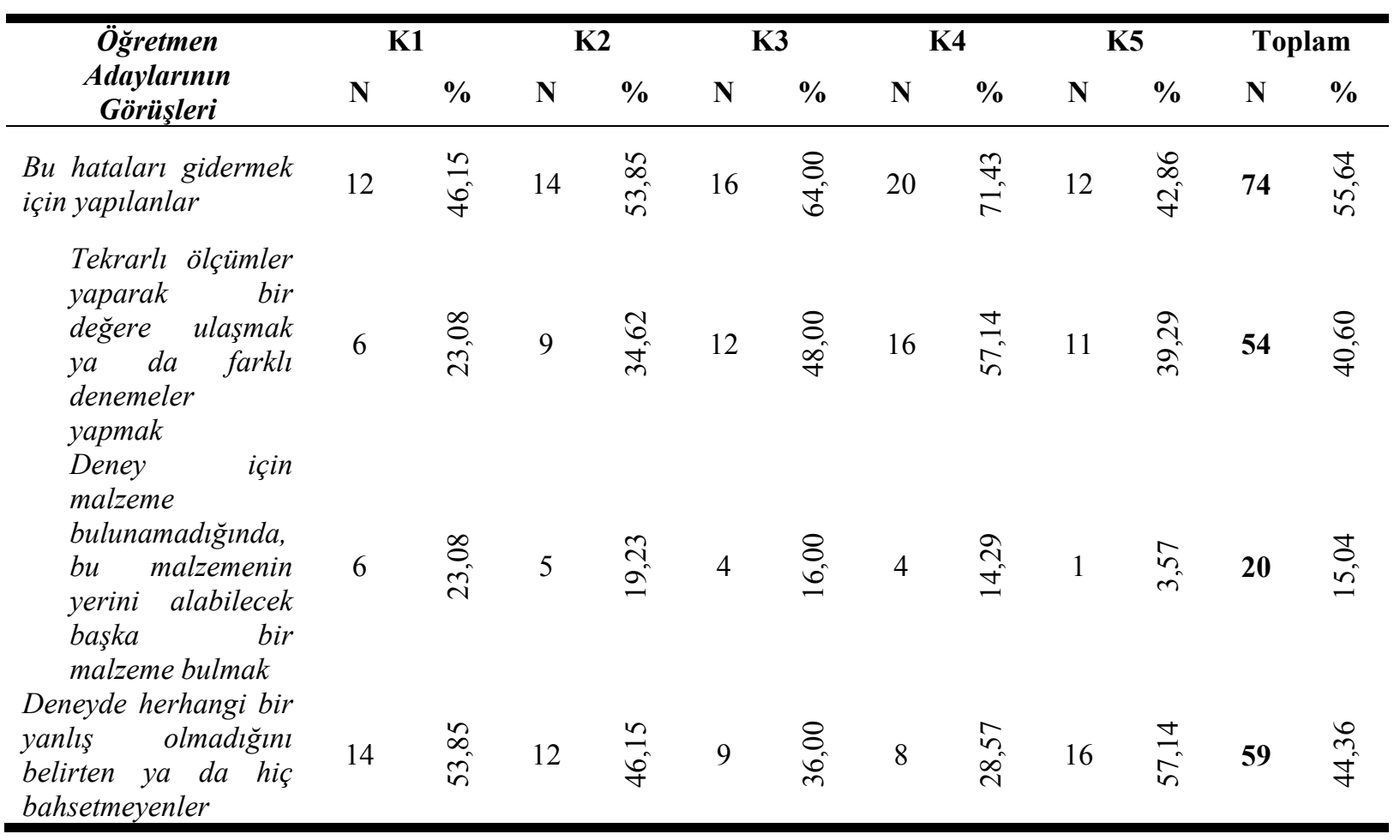

Öğretmen adaylarının 5 hafta boyunca tasarlamış oldukları deneylerin, ilköğretim ikinci kademe öğrencilerinin düzeyine uygun olup olmadığına ilişkin DDA 'dan edilen bulgular Tablo 14'te görülmektedir. Öğretmen adayları, yaptıkları deneylerin \%82,52 oranında ilköğretim düzeyindeki öğrencilere uygun olduğunu, \%11,2 oranında kısmen uygun gördükleri, \%6,3 oranında da uygun olmadığı şeklinde düşüncelerini belirtmişlerdir.

Tablo 14 Öğretmen Adaylarının Yaptıkları Deneylerin İlköğretim İkinci Kademe Öğrencilerinin Düzeyine Uygunluğu Hakkındaki Görüşlerine İlișkin DDA Sonuçları

\begin{tabular}{|c|c|c|c|c|c|c|c|c|c|c|c|c|c|}
\hline \multirow{2}{*}{\multicolumn{2}{|c|}{$\begin{array}{c}\text { Öğretmen Adaylarının } \\
\text { Görüssleri }\end{array}$}} & \multicolumn{2}{|c|}{ K1 } & \multicolumn{2}{|c|}{ K2 } & \multicolumn{2}{|c|}{ K3 } & \multicolumn{2}{|c|}{ K4 } & \multicolumn{2}{|c|}{ K5 } & \multicolumn{2}{|c|}{ Toplam } \\
\hline & & $\mathbf{N}$ & $\%$ & $\mathbf{N}$ & $\%$ & $\mathbf{N}$ & $\%$ & $\mathbf{N}$ & $\%$ & $\mathbf{N}$ & $\%$ & $\mathbf{N}$ & $\%$ \\
\hline $\begin{array}{l}\text { Evet, } \\
\text { hazırbulunuşluk } \\
\text { uygundur. }\end{array}$ & $\begin{array}{r}\text { ögrencilerin } \\
\text { düzeyine }\end{array}$ & 26 & $\begin{array}{l}8 \\
8 \\
8\end{array}$ & 20 & $\begin{array}{l}\widehat{\alpha} \\
\text { हे }\end{array}$ & 17 & ลิ & 22 & $\underset{n}{n}$ & 27 & $\begin{array}{l}8 \\
8 \\
8\end{array}$ & 118 & $\begin{array}{l}\text { กี } \\
\text { î }\end{array}$ \\
\hline $\begin{array}{l}\text { Klsmen } \\
\text { hazırbulunuşluk } \\
\text { uygundur. }\end{array}$ & $\begin{array}{r}\text { ögrencilerin } \\
\text { düzeyine }\end{array}$ & 0 & 8 & 5 & $\begin{array}{l}\tilde{\imath} \\
\text { }\end{array}$ & 3 & $\begin{array}{l}\Xi \\
\Xi\end{array}$ & 5 & $\stackrel{\infty}{\infty}$ & 3 & $\begin{array}{l}8 \\
0\end{array}$ & 16 & $\stackrel{\Rightarrow}{=}$ \\
\hline $\begin{array}{l}\text { Ögrencilere } \\
\text { önbilgiler } \\
\text { uygun olur }\end{array}$ & $\begin{array}{r}\text { gerekli } \\
\text { hattrlatılirsa }\end{array}$ & 0 & 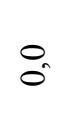 & 2 & $\therefore$ & 1 & $\hat{m}$ & 2 & $\underset{\sim}{ \pm}$ & 2 & రీ & 7 & $\underset{f}{\stackrel{一}{f}}$ \\
\hline Diğer & & 0 & $\begin{array}{l}8 \\
0\end{array}$ & 3 & $\stackrel{n}{=}$ & 2 & $\underset{\sim}{\stackrel{9}{n}}$ & 10 & $\hat{0}$ & 1 & $\stackrel{m}{m}$ & 9 & గ్లి \\
\hline
\end{tabular}


Tablo 14 Devamı

\begin{tabular}{|c|c|c|c|c|c|c|c|c|c|c|c|c|}
\hline \multirow{2}{*}{$\begin{array}{c}\text { Öğretmen Adaylarının } \\
\text { Görü̈şleri }\end{array}$} & \multicolumn{2}{|c|}{ K1 } & \multicolumn{2}{|c|}{ K2 } & \multicolumn{2}{|c|}{ K3 } & \multicolumn{2}{|c|}{ K4 } & \multicolumn{2}{|c|}{ K5 } & \multicolumn{2}{|c|}{ Toplam } \\
\hline & $\mathbf{N}$ & $\%$ & $\mathbf{N}$ & $\%$ & $\mathbf{N}$ & $\%$ & $\mathbf{N}$ & $\%$ & $\mathbf{N}$ & $\%$ & $\mathbf{N}$ & $\%$ \\
\hline $\begin{array}{lr}\text { Hayır, } & \text { ögrencilerin } \\
\text { hazırbulunuşluk } & \text { düzeyine } \\
\text { uygun değil } & \end{array}$ & 0 & O. & 1 & $\begin{array}{l}\infty \\
\infty \\
m\end{array}$ & 7 & चे & 1 & $\begin{array}{l}\hat{n} \\
m\end{array}$ & 0 & : & 9 & సิ \\
\hline $\begin{array}{l}\text { Deney öğrenciler için } \\
\text { karmaşık bir deneydir. }\end{array}$ & 0 & $\ddot{0}$ & 0 & : & 6 & $\begin{array}{l}\tilde{N} \\
\tilde{v}\end{array}$ & 0 & : & 0 & $\ddot{0}$ & 6 & $\underset{\stackrel{\overbrace{}}{\sim}}{\stackrel{+}{+}}$ \\
\hline Diğer & 0 & 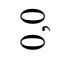 & 1 & ले & 1 & $\hat{n}$ & 1 & $\stackrel{b}{m}$ & 0 & $\stackrel{0}{0}$ & 3 & $\vec{i}$ \\
\hline
\end{tabular}

Öğretmen adaylarına uygulanan öğretim yönteminin onlara katkı sağlayıp sağlamadığına ilişkin düşünceleri Tablo $15^{\prime}$ de verilmektedir. Buna ilişkin öğretmen adaylarının \%97 oranında uygulamayı çeşitli nedenlerle faydalı gördükleri belirlenmiştir. Buna karşın yaklaşık \%1 oranında zararlı olduğunu düşündükleri görülmektedir.

Tablo 15 Öğretmen Adaylarının, Uygulanan Yöntemin Yararları/Zararları Hakkındaki Görüşlerine İlișkin DDA Sonuçları

\begin{tabular}{|c|c|c|c|c|c|c|c|c|c|c|c|c|}
\hline \multirow{2}{*}{$\begin{array}{c}\text { Öğretmen Adaylarının } \\
\text { Görüşleri }\end{array}$} & \multicolumn{2}{|c|}{ K1 } & \multicolumn{2}{|c|}{ K2 } & \multicolumn{2}{|c|}{ K3 } & \multicolumn{2}{|c|}{ K4 } & \multicolumn{2}{|c|}{ K5 } & \multicolumn{2}{|c|}{ Toplam } \\
\hline & $\mathbf{N}$ & $\%$ & $\mathbf{N}$ & $\%$ & $\mathbf{N}$ & $\%$ & $\mathbf{N}$ & $\%$ & $\mathbf{N}$ & $\%$ & N & $\%$ \\
\hline $\begin{array}{ll}\text { Faydası } & \text { olduğunu } \\
\text { düşünü̈yorum. }\end{array}$ & 46 & $\begin{array}{l}\infty \\
\infty \\
\hat{\sigma}\end{array}$ & 38 & $\begin{array}{l}8 \\
\text { an }\end{array}$ & 46 & $\begin{array}{l}\hat{\infty} \\
\hat{a}\end{array}$ & 41 & $\begin{array}{l}\dot{8} \\
\dot{8}\end{array}$ & 38 & $\stackrel{0}{8}$ & 209 & $\stackrel{\vec{n}}{\hat{a}}$ \\
\hline $\begin{array}{l}\text { Bizim için deneyim } \\
\text { oldu. }\end{array}$ & 14 & $\begin{array}{l}n \\
\infty \\
\infty \\
\infty\end{array}$ & 8 & $\begin{array}{l}8 \\
8 \\
\text { ¿ }\end{array}$ & 7 & $\begin{array}{l}\text { के } \\
\pm\end{array}$ & 9 & $\begin{array}{l}\tilde{\omega} \\
\hat{\sim}\end{array}$ & 6 & $\stackrel{2}{n}$ & 44 & fิ \\
\hline $\begin{array}{ll}\text { Eski } & \text { bilgilerin } \\
\text { pekişmesi } & \text { ve pratik } \\
\text { hale } & \text { geçmesini } \\
\text { sağladl. } & \end{array}$ & 12 & $\underset{\stackrel{a}{+}}{\stackrel{d}{d}}$ & 6 & $\begin{array}{l}8 \\
\therefore\end{array}$ & 4 & $\begin{array}{l}\bar{n} \\
\infty \\
\infty\end{array}$ & 5 & $\begin{array}{l}\text { ते } \\
\text { తn }\end{array}$ & 8 & $\begin{array}{l}n \\
\stackrel{n}{n}\end{array}$ & 35 & 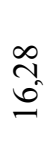 \\
\hline $\begin{array}{l}\text { Deney düzeneği } \\
\text { oluşturma ve deney } \\
\text { tasarlama becerimizi } \\
\text { geliştirdi. }\end{array}$ & 8 & $\begin{array}{l}m \\
\text { } \\
\sigma_{0}\end{array}$ & 6 & $\begin{array}{l}8 \\
\text { in }\end{array}$ & 7 & $\begin{array}{l}\text { के } \\
\pm\end{array}$ & 7 & $\hat{s}$ & 6 & $\begin{array}{l}2 \\
\therefore\end{array}$ & 34 & $\begin{array}{l}\vec{\infty} \\
\stackrel{n}{\imath}\end{array}$ \\
\hline $\begin{array}{l}\text { Eksiklerimizi } \\
\text { görmemiz ve bunlart } \\
\text { gidermemiz için iyi } \\
\text { oldu. }\end{array}$ & 0 & 8 & 8 & $\begin{array}{l}8 \\
\text { in }\end{array}$ & 10 & $\begin{array}{l}\hat{\lambda} \\
\text { ì }\end{array}$ & 4 & $\frac{2}{a}$ & 7 & $\underset{\substack{\mathfrak{y} \\
\infty}}{-}$ & 29 & $\underset{g}{g}$ \\
\hline $\begin{array}{l}\text { Teorik bilgilerimizi } \\
\text { uygulama firsatı } \\
\text { bulduk. }\end{array}$ & 0 & 8 & 4 & 8 & 7 & 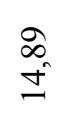 & 7 & o. & 7 & $\stackrel{\mathscr{T}}{\underset{\infty}{\infty}}$ & 25 & $\hat{\sigma}$ \\
\hline $\begin{array}{l}\text { Deneyi yapabilme } \\
\text { becerimize } \quad k a t k l \\
\text { sağlayarak } \\
\text { aktifleștik. }\end{array}$ & 7 & $\begin{array}{l}\infty \\
\stackrel{\infty}{\sim} \\
\stackrel{ \pm}{\sim}\end{array}$ & 2 & $\begin{array}{l}8 \\
\text { in }\end{array}$ & 1 & $\frac{m}{i}$ & 7 & $\tilde{\simeq}$ & 2 & $\begin{array}{l}\text { N } \\
\text { nn }\end{array}$ & 17 & $\bar{\sigma}$ \\
\hline Diğer & 6 & 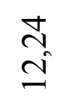 & 4 & @ & 10 & $\stackrel{\infty}{\stackrel{n}{\sim}}$ & 2 & $\stackrel{2}{2}$ & 2 & $\begin{array}{l}\text { in } \\
\text { in }\end{array}$ & 20 & $\begin{array}{l}\underset{\mathbb{J}}{\Xi} \\
=\end{array}$ \\
\hline
\end{tabular}


Tablo 15 Devamı

\begin{tabular}{|c|c|c|c|c|c|c|c|c|c|c|c|c|}
\hline \multirow{2}{*}{$\begin{array}{c}\text { Öğretmen Adaylarının } \\
\text { Görüşleri }\end{array}$} & \multicolumn{2}{|c|}{ K1 } & \multicolumn{2}{|c|}{ K2 } & \multicolumn{2}{|c|}{ K3 } & \multicolumn{2}{|c|}{ K4 } & \multicolumn{2}{|c|}{ K5 } & \multicolumn{2}{|c|}{ Toplam } \\
\hline & $\mathbf{N}$ & $\%$ & $\mathbf{N}$ & $\%$ & $\mathbf{N}$ & $\%$ & $\mathbf{N}$ & $\%$ & $\mathbf{N}$ & $\%$ & & $\%$ \\
\hline $\begin{array}{ll}\text { Zarar } & \text { verdiğini } \\
\text { düşünü̈yorum. }\end{array}$ & 2 & $\begin{array}{l}\infty \\
\stackrel{+}{\circ}\end{array}$ & 0 & 8 & 0 & $\begin{array}{l}8 \\
8 \\
0\end{array}$ & 0 & $\begin{array}{l}8 \\
8 \\
0\end{array}$ & 0 & 8 & 2 & ò \\
\hline $\begin{array}{l}\text { Konuların basit } \\
\text { olmast bizi basit } \\
\text { deneylere yöneltti. }\end{array}$ & 1 & $\underset{i}{0}$ & 0 & 8 & 0 & : & 0 & \& & 0 & $0_{0}^{8}$ & 1 & f́ \\
\hline $\begin{array}{lc}\text { eksikliğinden } & \text { dolayl } \\
\text { olumsuz } & \text { tutum } \\
\text { geliştirmemize } & \text { neden } \\
\text { oldu. }\end{array}$ & 1 & $\begin{array}{l}\text { do } \\
\text { i }\end{array}$ & 0 & 8 & 0 & 8 & 0 & 8 & 0 & 8 & 1 & fó \\
\hline $\begin{array}{l}\text { Bu konuda herhangi bir } \\
\text { cevap verilmemis. }\end{array}$ & 1 & $\underset{i}{0}$ & 2 & $\begin{array}{l}8 \\
\text { in }\end{array}$ & 1 & $\vec{n}$ & 0 & 8 & 0 & \% & 4 & $\stackrel{0}{\infty}$ \\
\hline
\end{tabular}

Öğretmen adaylarının hangi aşamada daha çok sıkıntı yaşadıkları hakkındaki görüşlerini belirttikleri DDA sorusundan elde edilen sonuçlar Tablo 16'da görülmektedir.

Tablo 16 Öğretmen Adaylarının, Uygulamanın Hangi Bölümünde Sıkıntı Yaşadıklarına İlişkin DDA Sonuçları

\begin{tabular}{|c|c|c|c|c|c|c|c|c|c|c|c|c|}
\hline \multirow{2}{*}{$\begin{array}{c}\text { Öğretmen Adaylarının } \\
\text { Görü̈şleri }\end{array}$} & \multicolumn{2}{|c|}{ K1 } & \multicolumn{2}{|c|}{ K2 } & \multicolumn{2}{|c|}{ K3 } & \multicolumn{2}{|c|}{ K4 } & \multicolumn{2}{|c|}{ K5 } & \multicolumn{2}{|c|}{ Toplam } \\
\hline & $\mathbf{N}$ & $\%$ & $\mathbf{N}$ & $\%$ & $\mathbf{N}$ & $\%$ & $\mathbf{N}$ & $\%$ & $\mathbf{N}$ & $\%$ & $\mathbf{N}$ & $\%$ \\
\hline $\begin{array}{l}\text { Deneyin bir takım } \\
\text { aşamalarında zorluk } \\
\text { çekildi. }\end{array}$ & 27 & $\frac{0}{\infty}$ & 20 & $\begin{array}{l}\hat{6} \\
\overline{8}\end{array}$ & 27 & $\begin{array}{l}8 \\
i \\
2\end{array}$ & 26 & $\begin{array}{l}\hat{n} \\
\hat{R}\end{array}$ & 26 & $\stackrel{n}{\infty}$ & 126 & $\begin{array}{l}8 \\
\text { na }\end{array}$ \\
\hline $\begin{array}{l}\text { Deney öncesinde } \\
\text { hangi değişkenler } \\
\text { üzerinde çalışılacağ } \\
\text { konusunda }\end{array}$ & 5 & $\frac{m}{6}$ & 3 & $\stackrel{8}{8}$ & 7 & $\stackrel{\nexists}{\stackrel{\nabla}{2}}$ & 8 & 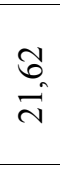 & 4 & 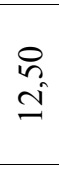 & 27 & $\hat{\text { ñ }}$ \\
\hline $\begin{array}{l}\text { Amaca uygun hipotezi } \\
\text { belirleme aşamasında }\end{array}$ & 6 & $\stackrel{n}{m}$ & 3 & $\stackrel{8}{0}$ & 5 & $\stackrel{\infty}{\infty}$ & 4 & $\begin{array}{l}\infty \\
\varrho\end{array}$ & 7 & $\begin{array}{l}\infty \\
\substack{\infty \\
\text { N }}\end{array}$ & 25 & $\begin{array}{l}8 \\
i \\
i\end{array}$ \\
\hline $\begin{array}{l}\text { Malzeme bulmak ve } \\
\text { bulamadı̆̆ımız } \\
\text { malzemelerin yerine } \\
\text { başka malzemeleri } \\
\text { koyma aşamasında }\end{array}$ & 5 & $\frac{m}{6}$ & 3 & 8 & 4 & $\begin{array}{l}\Xi \\
\equiv\end{array}$ & 6 & $\underset{\tilde{\sigma}}{\tilde{\sigma}}$ & 0 & \& & 18 & $\begin{array}{l}D_{0} \\
\subseteq \\
0\end{array}$ \\
\hline $\begin{array}{l}\text { Deney verilerini } \\
\text { yorumlayarak sonuç } \\
\text { çıkarma aşaması }\end{array}$ & 2 & in & 3 & $\stackrel{0}{0}$ & 4 & $\exists$ & 2 & $\begin{array}{l}\vec{F} \\
i n\end{array}$ & 5 & $\begin{array}{l}0 \\
i n\end{array}$ & 16 & J \\
\hline $\begin{array}{l}\text { Veri toplama } \\
\text { aşamasında } \\
\text { beklediğimiz olayların } \\
\text { gözlemlenmesi } \\
\text { aşamasinda }\end{array}$ & 2 & $\overbrace{6}^{n}$ & 3 & $\stackrel{8}{0}$ & 3 & $\hat{m}$ & 0 & 8 & 4 & \begin{tabular}{l}
8 \\
\hdashline \\
\hdashline
\end{tabular} & 12 & $\stackrel{\overbrace{}}{\sim}$ \\
\hline $\begin{array}{l}\text { Deney düzeneğini } \\
\text { kurarken }\end{array}$ & 1 & $\stackrel{\tilde{n}}{m}$ & 0 & \& & 1 & $\stackrel{\infty}{i}$ & 4 & $\begin{array}{l}\vec{\infty} \\
\stackrel{0}{0}\end{array}$ & 5 & $\begin{array}{l}0 \\
0 \\
n\end{array}$ & 11 & $\hat{6}$ \\
\hline
\end{tabular}


Tablo 16 Devamı

\begin{tabular}{|c|c|c|c|c|c|c|c|c|c|c|c|c|}
\hline \multirow{2}{*}{$\begin{array}{c}\text { Öğretmen Adaylarının } \\
\text { Görüssleri }\end{array}$} & \multicolumn{2}{|c|}{ K1 } & \multicolumn{2}{|c|}{ K2 } & \multicolumn{2}{|c|}{ K3 } & \multicolumn{2}{|c|}{ K4 } & \multicolumn{2}{|c|}{ K5 } & \multicolumn{2}{|c|}{ Toplam } \\
\hline & $\mathbf{N}$ & $\%$ & $\mathbf{N}$ & $\%$ & $\mathbf{N}$ & $\%$ & $\mathbf{N}$ & $\%$ & $\mathbf{N}$ & $\%$ & $\mathbf{N}$ & $\%$ \\
\hline $\begin{array}{l}\text { Deney sonucuna } \\
\text { ilişkin çeşitli } \\
\text { tahminler yürütme } \\
\text { aşamasinda }\end{array}$ & 5 & $\frac{m}{6}$ & 1 & $\stackrel{m}{m}$ & 1 & $\frac{\infty}{i}$ & 1 & $\frac{i}{i}$ & 1 & $\frac{m}{m}$ & 9 & 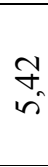 \\
\hline $\begin{array}{l}\text { Belirlenen } \\
\text { değişkenlerin } \\
\text { değiştirilmesi ve } \\
\text { kontrol edilmesi } \\
\text { aşamasinda }\end{array}$ & 1 & $\stackrel{\overbrace{}}{n}$ & 1 & $\stackrel{m}{m}$ & 2 & $\begin{array}{l}0 \\
n \\
n\end{array}$ & 0 & $\begin{array}{l}8 \\
0 \\
0\end{array}$ & 0 & $\begin{array}{l}8 \\
0 \\
0\end{array}$ & 4 & $\begin{array}{l}\nabla \\
\text { v }\end{array}$ \\
\hline Diğer & 0 & $\begin{array}{l}8 \\
\text { O. }\end{array}$ & 3 & $\begin{array}{l}0 \\
0 \\
0\end{array}$ & 0 & $\begin{array}{l}8 \\
0 \\
0\end{array}$ & 1 & $\stackrel{2}{i}$ & 0 & $\begin{array}{l}8 \\
\stackrel{0}{0}\end{array}$ & 4 & 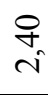 \\
\hline $\begin{array}{l}\text { Deneyin herhangi bir } \\
\text { aşamasında sıkıntı } \\
\text { çekilmedi. }\end{array}$ & 2 & $\stackrel{n}{\overbrace{0}}$ & 8 & $\begin{array}{l}\hat{\sigma} \\
\text { సै }\end{array}$ & 7 & $\begin{array}{l}\text { Ja } \\
\text { å }\end{array}$ & 11 & $\frac{m}{2}$ & 6 & $\stackrel{n}{\infty}$ & 34 & $\stackrel{\infty}{\stackrel{\infty}{+}}$ \\
\hline $\begin{array}{l}\text { Bu konuda herhangi bir } \\
\text { cevap verilmemiş. }\end{array}$ & 2 & 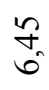 & 2 & $\begin{array}{l}\hat{6} \\
0\end{array}$ & 2 & $\begin{array}{l}\circ \\
n \\
n\end{array}$ & 0 & $\begin{array}{l}8 \\
0 \\
0\end{array}$ & 0 & $\begin{array}{l}8 \\
0 \\
0\end{array}$ & 6 & $\begin{array}{c}\bar{\sigma} \\
m\end{array}$ \\
\hline
\end{tabular}

Öğretmen adaylarının \%75'inin deneyin herhangi bir yerinde sıkıntı yaşadıklarını ifade eden görüşleri detayları incelendiğinde, $\% 16,3$ oranda değişkenleri belirleme konusunda sıkıntı yaşadıklarını, \%15,0 oranında hipoteze karar vermede sıkıntı yaşadıklarını, \%10,8 oranında da değişkenlere uygun malzeme bulma konusunda sıkıntı yaşadıkları Tablo 16'daki görüşler arasında ileri sürmüşlerdir. Deney esnasında herhangi bir sıkıntı yaşanmadığını belirten öğretmen adayları da oldukça fazla olup bunların oranı \%20,5'e yakın bir kısmı oluşturmaktadır.

\section{Sonuç ve Tartışma}

$\mathrm{Bu}$ çalışmada öğretmen adaylarına yönelik olarak geliştirilen akran öğretimi destekli bilimsel süreç becerileri laboratuvar yaklaşımının öğretmen adaylarının bazı bilimsel süreç becerilerine etkisi araştırılmıştır. Buna yönelik olarak da AUDY, ÖR, DDA ve yarı yapılandırılmış görüşmeler kullanılmıştır. Öğretmen adaylarına uygulanan AUDY'den elde edilen verilerin analizi, öğretmen adaylarının değişkenleri belirleme, sonuç çıkarma, hipotez kurma, değişkenleri değiştirme ve kontrol etme ve deney yapma becerilerinden bazılarının geliştiği, ancak bu gelişimin her beceri için farklı düzeyde olduğu bazılarında ise bir gelişim gözlemlenemediği görülmektedir. Bununla birlikte öğretmen adaylarına uygulanan ÖR'den de benzer bir sonuç elde edilmiş ancak AUDY'deki negatif değerlerin hiç birisine 
ulaşılamamıştır. Öğretmen adaylarının bu bilimsel süreç becerilerine ilişkin AUDY ve ÖR ortalama kazanç skorları Tablo 17'de görülmektedir.

Tablo 17 AUDY ve ÖR'den Elde Edilen Kazanç Skorları

\begin{tabular}{lcc}
\multicolumn{1}{c}{ Beceriler } & \multicolumn{2}{c}{ Kazanç Skorları } \\
& AUDY & ÖR \\
\hline Değişkenleri Belirleme Becerisi & 0,28 & 0,28 \\
Sonuç Çıkarma Becerisi & 0,71 & 0,19 \\
Hipotez Kurma Becerisi & $-0,12$ & 0,21 \\
Değişkenleri Değiştirme ve Kontrol & 0,27 & 0,25 \\
Etme Becerisi & $-0,06$ & 0,36 \\
Deney Yapma Becerisi & & \\
\hline
\end{tabular}

Akran öğretimi sürecindeki uygulanan AUDY'den elde edilen sonuçlar 1şığında değişkenleri belirleme ve değişkenleri değiştirme ve kontrol etme becerilerinde düşük düzeyde bir gelişme olduğu, sonuç çıkarma becerisinde de yüksek düzeyde bir kazanç olduğu görülmektedir. Buna karşın hipotez kurma ve deney yapma becerilerinde bir gelişme gözlenememiştir. ÖR'ya bakılığında da deney yapma becerisinin orta düzeyde geliştiği, diğer becerilerin de düşük düzeyde geliştiği şeklinde kazanç skorları görülmektedir (Tablo 17). ÖR ve AUDY arasındaki bu uyuşmazlığın öğretmen adaylarından kaynaklanan sebeplerden ileri geldiği düşünülmektedir. Öğretmen adayları bazı durumlarda sevmediği akranlarına çok yüksek puanlar vermiş, bazı durumlarda da grup puanlarında fazla bonkör davranmışlardır. Bunun yanı sıra, öğretmen adayları kendi sergiledikleri becerinin doğru olduğunu düşünerek akranlarını değerlendirdiklerinden bu da puan farklılığına neden olmuş olabilir.

Akran öğretimi destekli bilimsel süreç becerileri laboratuvar yaklaşımının bazı üst düzey bilimsel süreç becerilerini geliştirip geliştirmeyeceği hakkındaki bu çalışmada elde edilen, değişkenleri belirleme, sonuç çıkarma ve değişkenleri değiştirme ve kontrol etme becerilerindeki kazançlar, bu yöntemin becerileri geliştirebileceğini göstermiştir. Alan yazın incelendiğinde akran öğretimi yaklaşımının öğrencilerin kavramsal testlerdeki başarılarını arttırdığını, geleneksel problem çözme becerilerini geliştirdiğini göstermektedir (Eryılmaz, 2004; Sencar- Tokgöz, 2007; Crouch ve Mazur, 2001; Cortright, Collins ve DiCarlo, 2005). Ayrıca başka bir çalışma akran öğretiminin öğrencilerin anlama düzeylerini ve parçaları bir araya getirerek sentez yapma becerisini de geliştirdiğini göstermektedir (Cortright, Collins ve DiCarlo, 2005). Lancour (2005) bu becerilerin laboratuvar aktiviteleri ile geliştirilebileceğini belirterek, Şimşekli ve Çalış (2009) da laboratuvar çalışmalarının bilimsel süreç becerilerinin gelişiminde oldukça etkili olduğunu ifade etmiştir. Anagül ve Yaşar (2009) çalışmalarında bilimsel süreç becerilerinin laboratuvar etkinlikleri ile gelişiminin farklı düzeylerde olduğunu 
göstermektedir. Akran öğretimi ve bilimsel süreç becerilerine ilişkin alan yazın incelenmesi sonucunda ulaş1lanlarla birlikte akran öğretimi destekli bilimsel süreç becerileri laboratuvar yaklaşımı ile bilimsel süreç becerilerinin bazılarının geliştirilebileceği sonucuna ulaşılmıştır.

DDA'dan elde edilen bulgular incelendiğinde öğretmen adaylarının 6 hafta boyunca çeşitli bilgi eksiklerinden, konu ya da kavramlara ilişkin hatalarından dolayı sıkıntı çektikleri görülmüştür. Ayas, Coştu Karataş ve Ünal (2005) çalışmasında öğretmen adaylarının bilgi eksiklerinden dolayı deneyleri yeteri kadar yapamadıkları sonucuna ulaşmıştır. Benzer şekilde teorik açıdan sıkıntı yaşanmasının, pratikte zorlanmaya sebep olacağını gösteren farklı araştırmalar da görülmektedir (Sarıkaya ve Nakiboğlu, 1999; Aydoğdu, 1999). Öğretmen adaylarının deneyleri değerlendirirken kazanımlara ve öğrenci seviyesine uygunluğu hakkında olumlu görüşler belirtmesi, Küçükyılmaz ve Duban (2006)'ın öğretmen adaylarının, ilköğretim düzeyindeki deneyleri yapma konusunda olumlu düşünceleri olduğu şeklindeki sonucu ile benzeşmektedir. Ayrıca DDA'dan elde edilen öğretmen adaylarının düşüncelerine göre öğretim yönteminin; deneyim kazandırdı̆̆l, eski bilgileri pekiştirerek pratik hale getirdiği, deney düzeneği oluşturma ve deney tasarlama becerilerini geliştirdiği, eksiklerini görmeleri ve bunları gidermede etkili olduğu, teorik bilgiyi uygulama firsatı verdiği, deney yapma becerisini geliştirdiği yönünde katkı sağladığı sonucuna ulaşılmıştır. Bu sonuç Ayas ve diğerleri (2006)' nin çalışmasındaki bilgi ve beceri eksiklerini giderme yönünde katkı sağlayacağı sonucu ile benzerlik göstermektedir.

\section{Öneriler}

Bütün bu sonuçlar 1şığında yöntemin daha etkili hale getirilmesi için uygulayıcılara ve ileride yapılacak araştırmalara yön vermesi açısından çeşitli önerilerde bulunulabilir. $\mathrm{Bu}$ öneriler aşağıda görülmektedir.

* Akran öğretimi destekli bilimsel süreç becerileri laboratuvar yaklaşımı ile öğretmen adaylarının bilimsel süreç becerileri daha etkili bir şekilde geliştirilebilir. Bununla birlikte becerileri toplu bir şekilde ele almak yerine her beceri için bir ders saati ayırıp, becerileri de aşamalı olarak ele alarak daha etkili bir uygulama yapılabilir. Bu şekilde becerilerden elde edilen kazancın daha yüksek olacağı düşünülmektedir.

* Öğretmen adaylarının uygulama esnasında çeşitli zorluklarla karşılaşmalarının onlara çeşitli kazançlar sağladığı öne sürülebilir. Meslek 
* Akran öğretiminin laboratuvar ortamında kullanılmasına ilişkin bizlere bir fikir veren bu çalışmada kullanılan yöntem geliştirilerek, farklı değişkenlere olan etkisinin araştırılmasının ve yönteme ilişkin daha derinlemesine analizlerin yapılmasının alan yazına olumu katkılar sağlayacağı düşünülmektedir.

\section{Kaynakça}

A.A.A.S., (1998). Science Process Skills, Web: http://www.project2061.org/ publications/earlychild/online/experience/lind.htm Son Erişim Tarihi: Ocak 2011.

Anagül, Ş.S. ve Yaşar, Ş., (2009). İlköğretim Beşinci Sınıf Fen ve Teknoloji Dersinde Bilimsel Süreç Becerilerinin Geliştirilmesi. İlköğretim Online, 8(3), 844- 865.

Ayas, A., Coştu, B., Çalık, M., Karataş, F. Ö. ve Ünal, S. (2005). Fen Öğretmen Adaylarının Çözelti Hazırlama ve Laboratuvar Malzemelerini Kullanma Yeterliliklerinin Belirlenmesi. Hacettepe Üniversitesi Ĕgitim Fakültesi Dergisi, 28, 65-75.

Aydoğdu, B. (2006). İlköğretim fen ve teknoloji dersinde bilimsel süreç becerilerini etkileyen değişkenlerin belirlenmesi. Yayınlanmamış Yüksek Lisans Tezi, Dokuz Eylül Üniversitesi, Eğitim Bilimleri Enstitüsü, İzmir.

Aydoğdu, C., (1999). Kimya Laboratuvar Uygulamalarında Karşılaşılan Güçlüklerin Saptanması" Hacettepe Üniversitesi Eğitim Fakültesi Dergisi, 15, 30- 35.

Bayrak, H., (2005). İlköğretim 8. Sinıf Öğrencilerinin Kimyasal Bă̆lar Konusundaki Başarılarına, Öğrendikleri Bilgilerin Kalıcılı̆̆ına, Tutum ve Algılamalarına Çoklu Zeka Kuramına Dayalı Öğretimin Etkisi. Yüksek Lisans Tezi, Gazi Üniversitesi, Eğitim Bilimleri Enstitüsü, Ankara.

Beaumont-Walters, Y. \& Soyibo, K. (2001). An analysis of high school students' performance on five integrated science process skills. Research in Science \& Technological Education, 19(2), 133-145. 
Bozdoğan, A.E, Demirbaş, M. ve Taşdemir, A., (2006). Fen Bilgisi Öğretiminde İşbirlikli

Öğrenme Yönteminin Öğrencilerin Bilimsel Süreç Becerilerini Geliştirmeye Yönelik Etkisi. Inönü Üniversitesi Eğitim Fakültesi Dergisi, 7(11), 23- 36.

Chiappeta, E. L \& Koballa, T. R., (2002). Science Instruction in The Middle and Secondary Schools: Developing Fundamental Knowledge and Skills for Teaching, 6/E. Upper Saddle River, New Jersey: Pearson.

Chin, C., \& Chia, L. (2006)."Problem-Based Learning: Using Ill-Structured Problems in Biology Project Work. Science Education, 90(1), 44-67.

Cortright, R.N., Collins, H.L. \& DiCarlo, S.E. (2005). Peer Instruction Enhanced Meaningful Learning: Ability to Solve Novel Problems" The American Physiology Society 29, 107111.

Crouch, C. H. \& Mazur, E. (2001). Peer Instruction: Ten Years of Experience and Results" American Journal of Physics, 9(69), 970- 977.

Çepni, S., Ayas, A., Johnson, D. ve Turgut, F., (1997). Fizik Öğretimi:YÖK/Dünya Bankası Milli Ĕ̆itimi Geliştirme Projesi, Hizmet Öncesi Eğitimi, YÖK 1997. Ankara: Bilkent.

Demirci, N., (2005). Fizik Öğretiminin Yeniden Gözden Geçirilme İhtiyacı ve Bazı Geleneksel Olmayan Öğretim Yöntemlerine Örnekler, 23. Uluslararası Fizik Kongresi, Muğla Üniversitesi.

Dönmez, F., (2007). Meslek Liselerinde Öğrenim Gören Öğrencilerin Bilimsel Süreç Beceri Düzeylerinin Belirlenmesi. Yüksek Lisans Tezi, Balıkesir Üniversitesi, Fen Bilimleri Enstitüsü, Balıkesir.

Ekici, E., Taşkın, S., ve Taşkın- Ekici, F., (2002). Fen Laboratuvarının İçinde Bulunduğu Durum. V. Ulusal Fen Bilimleri ve Matematik Kongresi Bildiriler Kitabı. Ankara: Milli Eğitim Basımevi.

Ekici, G. (2002). Biyoloji Öğretmenlerinin Laboratuvar Dersine Yönelik Tutumlarının Farklı Değişkenler Açısından İncelenmesi. V. Ulusal Fen Bilimleri ve Matematik Kongresi Bildiriler Kitabı, Ankara: Milli Eğitim Basımevi.

Ekici, G., (2006). Biyoloji Öğretmenlerinin Laboratuvar Kullanımı Öz-Yeterlilik Algıları. VII. Ulusal Fen Bilimleri Eğitimi Kongresi Bildiriler Kitabı. Ankara: Milli Eğitim Basımevi. Ergün, R., Şimşekli, Y., Çalış, S., Özdilek, Z., Göçmençelebi, Ş. ve Şanlı, M., (2011). The Effects of Inquiry-Based Science Teaching On Elementary School Students' Science 
Process Skills And Science Attitudes. Bulgarian Journal of Science and Education Policy (BJSEP) 1(5): 48- 68.

Eryılmaz, E., (2004). Akran Öğretiminin Lise Öğrencilerinin Fizik Başarısına ve Fizik Dersine Olan Tutumlarına Etkisi. Doktora Tezi, Orta Doğu Teknik Üniversitesi, Fen Bilimleri Enstitüsü, Ankara.

Gözütok, D., (2007). Öğretim İlke ve Yöntemleri. Ankara: Ekinoks Yayınevi.

Hake, R.R., (1998). Interactive- Engagement Versus Traditional Methods: A Six Thousands Student Survey of Mechanics Test Data for Introductory Physics Courses" American Journals of Physics 66(1), 64- 74

Hofstein, A. \& Lunetta, V.N., (1982). The Role of The Laboratory in Science Teaching: Neglected Aspects of Research. Review of Educational Research, 52, 201- 217.

Hofstein, A. \& Lunetta, V. N. (2004). The Laboratory in Science Education: Foundations for The Twenty-First Century. Science Education, 88, 28-54.

Howit, C. (2007). Pre-Service Elementary Teachers' Perceptions of Factors in A Holistic Methods Course Influencing Their Confidence in Teaching Science. Research in Science Education, 37(1), 41-58.

Kanlı, U. ve Yağbasan, R. (2008). 7E Modeli Merkezli Laboratuvar Yaklaşımının Öğrencilerin Bilimsel Süreç Becerilerini Geliştirmedeki Yeterliliği", Gazi Üniversitesi Ĕ̌itim Fakültesi Dergisi, 28(1), 91-125.

Kanlı, U., (2007). 7E Modeli Merkezli Laboratuvar Yaklaşımı ile Doğrulama Laboratuvar Yaklaşımlarının Öğrencilerin Bilimsel Süreç Becerilerinin Gelişimine ve Kavramsal Başarılarına Etkisi. Doktora Tezi, Eğitim Bilimleri Enstitüsü, Gazi Üniversitesi, Ankara.

Kocakülah, M. S. ve Kocakülah, A. (2001) Illköğretim Fen Eğitiminde Yapılan Deneysel Çalışmalar ile İlgili Öğretmenlerin Görüşleri, Yeni Binyılın Başında Türkiye'de Fen Bilimleri Eğitimi Sempozyumu Kitapçığı, 7-8 Eylül 2001, Maltepe Üniversitesi, İstanbul.

Koray, Ö., Köksal, M. S., Özdemir, M., \& Presley, A.I. (2007). The Effect of Creative and Critical Thinking Based Laboratory Applications on Academic Achievement and Science Process Skills. Elementary Education Online, 6(3), 377-389. 
Küçükyılmaz, A. ve Duban, N., (2006). Sınıf Öğretmeni Adaylarının Fen Öğretimi ÖzYeterlik İnançlarının Arttırılabilmesi için Alınacak Önlemlere İlişkin Görüşleri. Yüzüncü Yıl Üniversitesi Eğitim Fakültesi Dergisi, 2(3), 1- 23.

Lancour, K.L., (2005). Science Process Skills, Web: http://www.tufts.edu/as/wright_center/products/sci_olympiad/pslsl_training_hammond. pdf, Son Erişim Tarihi: Ocak 2011,

Marx, J.D. \& Cummings, K., (2007). Normalized change. American Journal of Physics 57(1), 87-91.

Mazur, E., (1997). Peer Instruction: A User's Manual. NJ: Prentice Hall.

Mbewe, S., Chabalengula, V.M. \& Mumba, F. (2010). Pre-service teachers' familiarity, interest and conceptual understanding of science process skills. Problems of Education in the 21th Century, 22, 76-86.

MEB, Talim Terbiye Kurulu (2006). İlkögretim Fen ve Teknoloji Dersi (6, 7 ve 8 Siniflar) Öğretim Programı. Ankara: MEB yayınları.

Michael, B.L. \& Gifford V.D. (1995). The Effect of Computer-Assisted Instruction on the Science Process Skills of Community College Students. Paper presented at the Annual Meeting of the Mid-South Educational Research Association.

Nakiboğlu, C. ve Sarıkaya, S., (1999). Ortaöğretim Kurumlarında Kimya Derslerinde Görevli Öğretmenlerin Laboratuardan Yararlanma Durumunun Değerlendirilmesi. Dokuz Eylül Üniversitesi Buca Ĕ̆itim Fakültesi Dergisi, Özel Sayl, (11), 395.

Palmer, D. (2006). Sources of Self-efficacy in A Science Methods Course for Primary Teacher Education Students. Research in Science Education, 36, (4) 337-353.

Parim, G., (2009). The Effect of Inquiry on The Scientific Process Skills of 8th Grade Students As Related to Photosynthesis. European Science Education Research Association [ESERA] Conference. Oral Presentation, 31 Ağustos- 4 Eylül, İstanbul.

Pilzer, S., (2001). Peer Instruction in Physics and Mathematics. PRIMUS 11(2), 185- 192.

Sencar- Tokgöz, S., (2007). Akran Öğretiminin Altıncı Sinıf Öğrencilerinin Fen Bilgisi Dersi Başarılarına ve Fen Dersine Olan Tutumlarına Etkisi. Doktora Tezi. Orta Doğu Teknik Üniversitesi, Fen Bilimleri Enstitüsü, Ankara. 
Şensoy, Ö., Yalçın, N., Yıldırım, H.İ. ve Telli, A. (2004). İlköğretim 7. Sınıflarda Basit

Makineler Konusunun Öğretiminde Laboratuvar Yönteminin Öğrenci Başarısına

Etkisinin Araştırılması. GÜ, Gazi Eğitim Fakültesi Dergisi, 24(3), 291-305.

Settlage, J. \& Southerland, S.A., (2007). Teaching Science to Every Child: Using Culture As A Starting Point. Routledge: New York.

Şimşekli, Y. ve Çalış, S., (2008). Sınıf Öğretmenliği Öğrencilerinde Bilimsel Süreç Becerilerinin Gelişimine Fen Bilgisi Laboratuvarı Dersinin Etkisi. Eğitim Fakültesi Dergisi, 21(1), 183-192.

Suppapittayaporn, D. Emarat, N. \& Arayathanitkul, K., (2010). The Effectiveness of Peer Instruction and Structured Inquiry on Conceptual Understanding of Force and Motion: A Case Study From Thailand. Research in Science \& Technology Education, 28(1), $63-$ 79.

Temel, S. ve Morgil,İ., (2007). Kimya Eğitiminde Laboratuvarda Problem Çözme Uygulamasının Öğrencilerin Bilimsel Süreç Becerilerine ve Mantıksal Düşünme Yeteneklerine Etkisi. Dokuz Eylül Üniversitesi Buca Eğitim Fakültesi Dergisi 22: 8997.

Vygotsky, L. (1978). Mind in Society. Cambridge, MA: Harvard University Press.

Walters, Y. and Soyibo, K. (2001). An Analysis of High School Students' Performance on Five Integrated Science Process Skills. Research in Science and Technology Education 2(19) 133- 145.

Webb, C (1993). "Teacher Perceptions of Professional Development Needs and The Implementations of The K- 6 Science and Technology Syllabus". Research in Science Education, 23, 327- 336.

Zion, M., Cohen, S., \& Amir, R. (2007). The Spectrum of Dynamic Inquiry Teaching Practice. Research in Science Education, 37(4),423-447. 